\title{
Aminophosphonate mineralisation is a major step in the global oceanic phosphorus redox cycle
}

\section{Andrew Murphy}

University of Warwick

\section{David Scanlan}

University of Warwick https://orcid.org/0000-0003-3093-4245

\section{Yin Chen}

University of Warwick https://orcid.org/0000-0002-0367-4276

\section{Andrew Bottrill}

Medical Research Council Toxicology Unit, University of Leicester https://orcid.org/0000-0002-51823643

\section{Gary Bending}

University of Warwick

John Hammond

University of Reading https://orcid.org/0000-0002-6241-3551

\section{Elizabeth Wellington}

Warwick University

lan Lidbury ( $\square$ I.lidbury@sheffield.ac.uk)

University of Sheffield https://orcid.org/0000-0001-7190-315X

\section{Article}

Keywords: Planktonic Synthesis, Organophosphorus, Aminophosphonate Uptake, Marine Heterotrophs, Mesopelagic and Epipelagic Waters, Regenerated Phosphate

Posted Date: December 18th, 2020

DOl: https://doi.org/10.21203/rs.3.rs-114998/v1

License: (c) (i) This work is licensed under a Creative Commons Attribution 4.0 International License. Read Full License

Version of Record: A version of this preprint was published at Nature Communications on July 27th, 2021. See the published version at https://doi.org/10.1038/s41467-021-24646-z. 
1 Aminophosphonate mineralisation is a major step in the global oceanic phosphorus redox

2 cycle

3 Andrew R. J. Murphy ${ }^{1}$, David J. Scanlan ${ }^{1}$, Yin Chen ${ }^{1}$, Andrew Bottrill ${ }^{1}$, Gary Bending ${ }^{1}$, John P.

4 Hammond $^{2}$, Elizabeth M. H. Wellington ${ }^{1}$, Ian D.E.A. Lidbury ${ }^{3 *}$

$5{ }^{1}$ School of Life Sciences, University of Warwick, Gibbet Hill Road, Coventry, UK

62 School of Agriculture, Policy, and Development, University of Reading, Earley Gate,

7 Whiteknights, Reading, UK

$8{ }^{3}$ Department of Animal and Plant Sciences, University of Sheffield, Sheffield, UK

$9 \quad *$ Corresponding author: I.lidbury@sheffield.ac.uk

10

11

12

13

14

15

16

17

18

19 
Abstract

The planktonic synthesis of reduced organophosphorus molecules, such as alkylphosphonates and aminophosphonates, represents one half of a vast global oceanic phosphorus redox cycle. Whilst alkylphosphonates tend to accumulate in recalcitrant dissolved organic matter, aminophosphonates do not. Thus, we hypothesised unknown pathways for the uptake of aminophosphonates must exist in seawater. Here, we identify three novel bacterial 2-aminoethylphosphonate (2AEP) transporters, named AepXVW, AepP and AepSTU, whose expression is independent of phosphate concentrations (phosphateinsensitive). AepXVW, is found in diverse marine heterotrophs and is ubiquitously distributed in mesopelagic and epipelagic waters. Unlike the archetypal phosphate-regulated phosphonate binding protein, PhnD, the newly identified AepX is heavily transcribed ( 100fold $>$ PhnD) in the global ocean independently of phosphate and nitrogen concentrations. Collectively, our data identifies a mechanism responsible for the oxidative step in the marine phosphorus redox cycle and suggests 2 AEP may be an important source of regenerated phosphate, which is required for oceanic primary production.

\section{Introduction}

Phosphonates are reduced organic phosphorus (P) molecules with a carbon (C)-P bond, as opposed to the more common C-oxygen (O)-P ester bonds found in many other organic P molecules ${ }^{1}$. Phosphonates are synthesised as both primary and secondary metabolites in various bacterial, archaeal and eukaryotic organisms ${ }^{1-7}$ where they are incorporated into lipids (phosphonolipids) and glycans (phosphonoglycans) ${ }^{4,8}$. A significant proportion can also be released from the cell to facilitate favourable biotic interactions ${ }^{9}$. Thus, they are ubiquitous in terrestrial and aquatic ecosystems ${ }^{10-14}$. Phosphonates also represent a 
major fraction of the marine organic phosphorus poo ${ }^{11,15-17}$ and recent studies have now identified several cosmopolitan marine microorganisms capable of synthesising significant quantities of these compounds ${ }^{6,7,9,18,19}$. Collectively, this synthesis drives a vast global oceanic phosphorus redox cycle with reduced phosphorus input in the surface ocean estimated to be an order of magnitude greater than pre-anthropogenic riverine phosphorus input ${ }^{9}$. Whilst much attention has focused on the degradation of alkylphosphonates, such as (hydroxy-) methylphosphonate (MPn) and 2-hydroxyethylphosphonate (HEP), as a source of $\mathrm{P}^{16,17,20,21}$, the potential for aminophosphonates such as 2-aminoethylphosphonate (2AEP) to serve as sources of $\mathrm{C}$ and $\mathrm{N}$ (Pi-insensitive) has been neglected. However, emerging evidence suggests that Pi-insensitive 2AEP catabolism occurs in nature ${ }^{22,23}$. Notably, the absence of 2AEP from otherwise phosphonate rich high molecular weight (HMW) DOM ${ }^{16,17}$, despite its supposed ubiquitous production ${ }^{9,19,24,25}$, suggests preferential catabolism of this molecule in comparison to alkylphosphonates.

The C-P bond is resistant to the activity of standard inorganic phosphate (Pi) liberating enzymes such as alkaline phosphatases and requires specific mechanisms to break, such as the C-P lyase ${ }^{26,27}$. Several 2AEP-specific phosphonate degradation systems (phosphonatases) have been characterised (Fig 1A). The C-P lyase, which is a non-specific promiscuous phosphonatase, is only induced in response to Pi-starvation, being regulated by the twocomponent master regulator of the Pi-stress response regulon, $\mathrm{PhoBR}^{24}$. In marine surface waters, genes encoding the C-P lyase are enriched in bacterial genomes found in regions typified by low Pi concentration $\mathrm{s}^{20}$ where they are also heavily expressed ${ }^{28}$. Recent data has shown Pi-insensitive regulation of 2AEP degradation, facilitated by the 2AEP-specific phosphonatase systems, occurs in a few strains related to marine Alphaproteobacteria ${ }^{22}$ and a terrestrial Gammaproteobacteria ${ }^{23}$. In both cases, a major consequence of Pi-insensitive 
69

2AEP degradation was the remineralisation and release of labile $\mathrm{Pi}^{22}$, due to the greater cellular demand for $\mathrm{N}$ over $\mathrm{P}$ and the $1: 1 \mathrm{~N}: \mathrm{P}$ stoichiometry of 2AEP.

To date, only two 2-AEP transport systems have been identified. Both are ATP-binding cassette $(A B C)$ transporters which consist of a periplasmic substrate-binding protein (SBP), an ATP-binding domain protein, and a transmembrane permease. The first is located within the C-P lyase operon (phnCDEFGHIJKLMNOP $)^{29,30}$ with genes encoding the SBP, ATP-binding domain and transmembrane domains designated $p h n D, p h n C$, and $p h n E$, respectively. The second is another ABC-transporter phnSTUV shown by Jiang et al. to complement a C-P lyase knockout mutant of $E$. coli together with $p h n W X^{31,32}$. PhnD has a restricted distribution in seawater whose abundance is highly correlated with regions of Pi-limitation ${ }^{20}$. However, no 2AEP transporter has been identified in the majority of bacteria possessing PhnWX and PhnWAY phosphonatases, which is surprising, given the fact 2AEP is a charged molecule and ubiquitous in marine and terrestrial ecosystems ${ }^{1,20}$.

Here, we sought to identify transporters, which provide superb molecular tools for investigating the in situ cycling of specific environmental metabolites ${ }^{28,33-35}$, required for $2 \mathrm{AEP}$ catabolism in environmental bacteria. Through combining laboratory-based molecular and genetic analyses with environmental meta-omics, we identified three novel transporters which have a role in 2AEP uptake and revealed Pi-insensitive 2AEP catabolism is widespread in the global ocean, likely representing a major step in the marine phosphorus redox cycle. 
Results

Pseudomonas putida BIRD-1 possesses a novel Pi-sensitive 2-aminoethylphosphonate ABC transporter, AepXVW

We recently identified several candidate 2-AEP transporters (ABC-type) in Pseudomonas rhizobacteria that contain the PhnWX phosphonatase but lack both the archetypal PhnCDE transporter and PhnSTUV' ${ }^{36}$ (Fig 1A). In Pseudomonas putida BIRD-1 (hereafter BIRD-1), a periplasmic substrate binding protein associated with one of these putative transporters (PPUBIRD1_4925), which we hereafter refer to as AepX, was induced under Pi-deplete growth conditions in a PhoBR-dependent manner ${ }^{36}$. AepX belongs to the same family (pfam13343) as PhnS, iron and sulphate SBPs but is clearly distinct (Coverage = $40 \%$, Identity $\left.=25.09 \%, 1.1 \mathrm{e}^{-05}\right)($ Fig $1 \mathrm{~B})$.

BIRD-1 was capable of growth on $1.5 \mathrm{mM}$ 2AEP as either a sole $\mathrm{N}, \mathrm{P}$, or $\mathrm{N}$ and P source, the latter resulting in mineralisation of Pi which was subsequently exported from the cell (Fig 1C, Fig S1). Mutagenesis of phnWX confirmed this phosphonatase was essential for 2AEP catabolism under both growth conditions in this bacterium (Fig S2A and S2B). Next, we investigated if AepX and its corresponding $A B C$ transporter components, the ATP binding domain protein (AepV), and the permease domain protein (AepW) were essential for its growth on 2AEP. Surprisingly, deletion of aepXVW ${ }^{B / R D}$ had no effect on growth as a sole $\mathrm{N}$ source (Fig 1C). However, the mutant $\left(\triangle a e p X V W^{B R D}:: G m\right)$ had significantly $(P<0.0001)$ attenuated growth on 2AEP as a sole P source (Fig 1C). The growth defect observed during growth on 2AEP as a sole P source was largely restored by complementing the mutant with a plasmid-encoded native homolog (Fig. 1C). These data suggest that whilst the aepXVW transporter is not essential, it is involved in 2AEP uptake as a sole P source but is not involved 
in its growth as an $\mathrm{N}$ source. Therefore, another 2AEP transport system must also exist in this bacterium.

Identification of two Pi-insensitive 2-aminoethylphosphonate transporters in P. putida BIRD-1

Next, by subjecting the BIRD-1 $\triangle a e p X V W^{B I R D}:: g m$ mutant to comparative proteomics, we identified a major facilitator-type (MFS) transporter, (PPUBIRD1_3129), hereafter referred to as AepP for 2-aminoethylphosphonate permease, whose expression was significantly increased during growth on 2 AEP as a sole $\mathrm{N}$ source (Pi-insensitive) (Fig S3). AepP is related to the glycerol-3-phosphate (G3P): Pi antiporter, GlpT ${ }^{37,38}$ (identity to GlpT $=27.75 \%, 9 \mathrm{e}^{-37}$ ), a member of the organophosphate: phosphate antiporter (OPA) family of MFS transporters. AepP shares conserved residues essential for binding Pi and the phosphate moiety of G3P39${ }^{42}$ with GIpT, whereas residues that impact the binding affinity to the glycerol moiety of G3P but not Pi are not conserved ${ }^{41}$ (Fig S4). Mutation of aepP in either the wild type parental strain $(\triangle a e p P$, Fig1D) or the aepXVW mutant ( $\triangle a e p X V W: G m: a e p P$, Fig 1E) led to an inability to grow mutant, revealing the presence of a third 2AEP transporter in this bacterium. S3). Another substrate binding protein (PPUBIRD1_3891) containing the same pfam domain (pfam13343) as AepX (Fig 1B), hereafter named AepS, was constitutively expressed in all growth conditions. In order to uncover the role of AepS in the utilisation of 2AEP as a sole $\mathrm{P}$ source, a triple mutant $\triangle a e p X V W: G m$;aepP:aepSTU was generated in BIRD-1 (Fig 1E). This 
triple knockout mutant was unable to grow on $2 A E P$ as a sole $P$ source (Fig $1 E$ ), suggesting AepSTU is a functional 2AEP transporter. However, generation of a single aepSTU knockout mutant did not affect Pi-sensitive growth compared to the wild type (Fig S2C), suggesting AepXVW is the major transporter involved in Pi-sensitive 2AEP uptake and AepSTU only has an auxiliary role in 2AEP uptake. Despite expression of AepS during Pi-insensitive growth (Fig S3), this transporter was unable to facilitate growth on 2AEP as a sole $\mathrm{N}$ source in the absence ORFs encoding AepXVW were located adjacent to ORFs encoding the phosphonatases,

AepXVW is found in several marine bacteria capable of Pi-insensitive mineralisation and is a functional 2-aminoethylphosphonate transporter

Using PPUBIRD1_4925 (AepX) as the query, we scrutinised the genomes of several isolates related to marine Rhodobacteraceae (Stappia spp., Terasakiella spp., Falsirhodobacter spp.) capable of Pi-insensitive phosphonate catabolism ${ }^{22}$. ORFs encoding orthologs of AepX were identified in the genomes of Stappia stellulata DSM 5886 and Terasakiella pusilla DSM 6293, in addition to several other marine roseobacter strains: Aliiroseovarius crassostreae (DSM 16950), Aliiroseovarius sediminilitoris (DSM 29439), Shimia marina (DSM 26895), and Thalassobius aestuarii (DSM 15283) (Fig 2A). We also found an orthologous ORF in the model rhizosphere alphaproteobacterium Sinorhizobium meliloti strain 1021 that is capable of 2AEP catabolism via a phosphonatase ${ }^{43}$ (Fig $2 \mathrm{~A}$ ). In all cases, PhnWAY or PhnWX, strongly suggesting a role in 2AEP transport. S. stellulata DSM 5886, A. 
DSM 15283 were all capable of growth on 2AEP as either the sole $\mathrm{N}$ or P source (Table S1). Indeed, both Aliiroseovarius strains lack other characterised 2AEP transport and degradation systems (Table S2). As previously reported, Pi was exported from cells and accumulated in the medium during growth on 2AEP as a sole $\mathrm{N}$ source (Fig S5A).

To confirm that Stappia AepXVW can take up 2AEP, we complemented the BIRD-1 null 2AEP transporter mutant ( $\triangle a e p X V W: a e p P: a e p S T U: g m)$ with this transporter fused with the stellulata AepXVW is also a functional 2AEP transporter. expressed during growth on 2AEP as either a sole $\mathrm{N}$ or $\mathrm{P}$ source, as was the phosphonatase

AepXVW is highly expressed in the marine bacterium Stappia stellulata during Pi-sensitive and Pi-insensitive growth on 2-aminoethylphosphonate

In BIRD-1, AepXVW was only involved in Pi-sensitive growth whilst AepP was induced during Pi-insensitive metabolism (Fig 1). However, S. stellulata lacks AepP but is still capable of Pi-insensitive growth and $\mathrm{Pi}$ export (Fig S5A). In addition to aepXVW and genes encoding the 2AEP phosphonatase (phnWAY), S. stellulata also possesses genes (phnCDEFGHIJKLMN) encoding the P-regulated C-P lyase operon and we also confirmed this strain grew on several other alkylphosphonates as sole P source (Fig S5B). Therefore, to determine which transport and degradation systems were upregulated during growth on 2AEP as either a sole $\mathrm{N}$ or $\mathrm{P}$ source, we performed comparative proteomics. Unlike BIRD-1, AepX was abundantly (PhnWAY), whilst the C-P lyase operon was not (Fig 3). Importantly, whilst we detected several general nitrogen stress-response proteins induced under Pi-insensitive growth, we 
didn't identify any other potential 2AEP transporters (Table S3). Therefore, unlike in BIRD-1, AepXVW likely represents the major route for 2AEP uptake in this bacterium.

aepX and aepP are found in distantly related and cosmopolitan bacterial taxa

Using the Integrated Microbial Genomes/Microbiomes from the Joint Genome

Institute (IMG/M/JGI) database, we identified ORFs encoding AepX and AepP (but not AepS)

in genomes retrieved from both taxonomically divergent isolates as well as single amplified genomes (SAGs) and metagenome assembled genomes (MAGs), which revealed an unexpected diversity for these substrate binding proteins (Fig 4). For AepX, this included cosmopolitan marine Alphaproteobacteria other than Rhodobacteraceae, marine Deltaproteobacteria, as well as marine Vibrio spp. AepX was also found in terrestrial Betaproteobacteria, Firmicutes, and other gram-positive bacteria (Fig 4). AepX was partitioned into several subclades, with Aep $\mathrm{X}^{\text {Stappia }}$ and AepX $\mathrm{X}^{B I R D}$ well separated (Fig 4). Many taxonomically divergent AepX ORFs were co-localised with ORFs encoding the various phosphonatase systems or the C-P lyase, supporting a role in 2AEP transport (Fig 4).

AepP was also found in a wide range of phylogenetically divergent taxa, such as Acidobacteria (Granuliella mallensis) and Bacteroidetes (Kriegella aquimaris), Actinobacteria localised with ORFs encoding phosphonatases (Fig S6). Notably, AepP was found in fewer marine isolates compared to AepX. 

global ocean Using the TARA oceans OM-RGCv2+G metagenome (MG) and OM-RGCv2+T metatranscriptome (MT) datasets ${ }^{44}$, we calculated the abundance of our newly-identified aepX, aepS and aepP transporters and compared this with phnS and the archetypal phosphonate transporter phnD, whose gene abundance in seawater was recently calculated $^{20}$. We analysed data from both the epipelagic and mesopelagic zones where phosphonate mineralisation is believed to occur ${ }^{15}$. Across all oceanic sampling sites in both the epipelagic and mesopelagic, aepX gene and transcript abundance was significantly greater (MG; post-hoc Dunn's test $z=10.4, p<0.001$ and $z=4.8, p<0.001$, respectively) than phnD (Fig $5 \mathrm{~A}$ and $\mathrm{B})$. On average, in the mesopelagic almost $10 \%$ of bacterial cells possess aepX whilst only $\sim 0.3 \%$ and $0.5 \%$ possess $p h n D$ and aepP, respectively (Fig $5 A$ ). aepX transcription was 40 fold and 350-fold greater than phnD in the epipelagic and mesopelagic, respectively (Fig 5B). The majority of aepX sequences were related to the cosmopolitan Alphaproteobacteria and Deltaproteobacteria (Fig 4). We confirmed that these abundant environmental sequences were also co-localised with phosphonate degradation genes (Fig 4). In broad agreement with aepX, the cumulative transcription of the two phosphonatase markers phnA and phnX is significantly greater than the C-P lyase marker phnJ (Kruskal-wallis $X^{2}=206.6, p<0.001$ ) strengthening this observation that 2AEP mineralisation is a major oceanic process. aepX and phnD (post-hoc Dunn's test $z=13.1$ and 9.0, $p<0.001, z=14.5$ and 12.6, $p<0.001$, and $z=9.9$ and 8.9, $p<0.001$ respectively) in the epipelagic, whilst only aepS and phnS were 
significantly lower in the mesopelagic (post-hoc Dunn's test $z=10.1$ and $10.8, p<0.001$, and $z$ $=4.6$ and $5.5, p<0.001$ respectively) (Fig $5 A$ and $S 7$ ).

Unlike $p h n D$ and aepP, aepX abundance was comparable across all oceanic regions

within both MG and MT at each depth suggesting 2AEP mineralisation is a ubiquitous process in seawater (Fig 5C \&D). For all sites at each depth, the relative abundance of aepX transcripts was always significantly greater (Wilcoxon rank sum $W=3771, p<0.001$, estimated log2 difference $=2.24(95 \mathrm{Cl} 1.97-2.52)))$ than its own gene abundance. For phnD, we observed significantly greater transcript abundance compared to its own gene abundance only in the Mediterranean Sea, a region typified by Pi-depletion (Wilcoxon rank sum $W=0, p<0.001$, estimated $\log 2$ difference $=3.11(95 \mathrm{Cl} 1.90-4.42))$. Finally, in agreement with previous work ${ }^{20}$, phnD gene abundance was inversely correlated $\left(R^{2}=0.340, p<0.001\right)$ with standing stock concentrations of $\mathrm{Pi}$ (Fig 5E) as was phnD transcript abundance (Fig 5F). In contrast, aepX and aepP gene abundance were positively correlated $\left(R^{2}=0.098, p<0.001\right.$ and $R^{2}=0.291, p<0.001$, respectively) with $\mathrm{Pi}$ concentration (Fig $5 \mathrm{E}$ ), whilst no significant relationship between $\mathrm{Pi}$ independent of Pi in seawater globally.

To better understand the parameters controlling 2AEP catabolism in the ocean, we compared both gene abundance and transcript in relation to $\mathrm{R}^{*}$, a measure of $\mathrm{N}$ vs $\mathrm{P}$ limitation calculated as $\left[\mathrm{NO}_{2}\right]+\left[\mathrm{NO}_{3}\right]-16\left[\mathrm{PO}_{4}\right]$ (adapted from Smith et al. ${ }^{45}$ ). As expected, phnD gene and transcript abundance were positively correlated with $R^{*}\left(R^{2}=0.168, p<0.001\right.$ and $R^{2}=0.197$, $\mathrm{p}<0.001$, respectively (Fig $5 \mathrm{G}$ and $5 \mathrm{H}$ ), i.e. regions typified with Pi depletion, though notably Pi concentration alone was a better predictor of phnD gene abundance (Fig 5E). However, aepX and aepP gene abundance was (weakly) inversely correlated with $R^{*}\left(R^{2}=0.029, p<0.05\right.$ 
and $R^{2}=0.108, p<0.001$, respectively) (Fig 5G) and no significant relationship was found between $\mathrm{R}^{*}$ and aepX/aepP transcript abundance (Fig $\left.5 \mathrm{H}\right)$. These data are consistent with the proteomic response of S. stellulata under laboratory conditions and suggests AepX is induced in the presence of 2AEP (substrate-inducible) and not in response to nutrient limitation.

\section{Discussion}

Both phosphonate biosynthesis ${ }^{1,3,5,46}$ and catabolic ${ }^{1,23,25,43,47-52}$ genes are ubiquitous in marine, soil and gut microbiomes, suggesting phosphonate cycling is widespread in nature. In contrast, the uptake of these molecules is comparatively understudied, with only two characterised $A B C$ transport systems confirmed, both of which are linked solely to Pacquisition $^{29-31}$. The abundance of these Pi-sensitive transporters in marine systems is not equivalent to the abundance of catabolic genes ${ }^{20}$, especially those ( $p h n W A Y$ ) recently shown to be involved in Pi-insensitive catabolism ${ }^{22}$. This would suggest our knowledge of the microbial uptake of phosphonates, particularly 2AEP, is incomplete. Using transporter expression as a proxy for the cycling of specific nutrients has significantly advanced our understanding of in situ biogeochemical cycling $33,34,53$. This molecular approach helped resolve the biogenesis of the climate-active gas methane in oxygenated surface waters, driven through the uptake and degradation of methylphosphonate ${ }^{21}{ }^{28}$. Thus, a gap in mechanistic knowledge on 2AEP metabolism impairs our ability to survey the in situ cycling of reduced organophosphorus compounds, especially when high resolution separation of such compounds is difficult ${ }^{9,54}$. Here, identification of novel Pi-insensitive 2AEP transporters allowed us to develop molecular markers to investigate the cycling of 2AEP on a global scale and compare these with previously characterised Pi-sensitive markers. 
271 synthesised in the marine environment in relatively large quantitities ${ }^{1,3,9,25,54}$. However, several studies have shown 2AEP is absent in 'semi-labile' DOM whilst alkylphosphonates, such as MPn and HEP, tend to accumulate ${ }^{16,17,55}$. Collectively, this would suggest $2 A E P$ is more susceptible to microbial mineralisation ${ }^{22}$ and thus shorter residence times. Here, we reveal pathways for the Pi-insensitive uptake $(a e p X)$ and catabolism $(p h n A)$ are expressed at significantly higher levels across the global ocean than the Pi-repressible phnD and phnJ, providing a clear mechanism for this phenomenon. Our data also suggests 2AEP is preferentially mineralised independently of both $\mathrm{N}$ and $\mathrm{P}$ status explaining why phosphonates are metabolised in regions where phosphate concentrations are high enough to repress C-P lyase-expression ${ }^{20,21,56}$. Together, this adds further weight to the notion that phosphonates are rapidly cycled between reduced and oxidised forms $\mathrm{s}^{9,22}$ has previously been shown to mineralise organic $\mathrm{N}$ to ammonium which can cross feed into another bacterium ${ }^{57}$. Assuming the link between Pi-insensitive expression of AepXVW, PhnWAY and subsequent cellular export of mineralised Pi observed in our laboratory cultures and as demonstrated by Chen et al. ${ }^{22}$ is comparable to in situ metabolism, we provide a clear mechanism to support the hypothesis that phosphonates are a source of regenerated $\mathrm{Pi}$ throughout the water column ${ }^{15,22}$, especially at depths where AepP is also found in higher abundances. Thus, aminophosphonates likely represent another source of regenerated $\mathrm{Pi}$ from DOP, a mechanism which is important for maintaining biological production in $\mathrm{Pi}$ deplete regions of the ocean ${ }^{58,59}$. 
293 terrestrial bacteria capable of Pi-insensitive 2AEP catabolism. One of these, AepXVW, is the 294 most abundant phosphonate transporter in seawater and is ubiquitously transcribed at high 295 levels suggesting 2AEP mineralisation is a major process in the marine organic $\mathrm{C}, \mathrm{N}$ and $\mathrm{P}$ 296 cycles and may present a significant source of regenerated Pi available for oceanic production.

297 This conclusion is strengthened by two key observations: 1) AepX transcription is not 298 repressed by standing stock concentrations of $\mathrm{Pi}$, and 2) extracellular Pi export occurs during 299 Pi-insensitive 2AEP metabolism. Thus, we provide further evidence for the role of low 300 molecular weight phosphonates acting as a phosphorus currency between autotrophic and 301 heterotrophic microbes ${ }^{9}$. 


\section{Bacterial strains and growth conditions}

Pseudomonas strains used in this work were maintained on Luria Bertani (LB) agar

$307(1.5 \% \mathrm{w} / \mathrm{v})$ medium at $30^{\circ} \mathrm{C}$. Stappia stellulata and the Roseobacter strains were maintained on Marine Broth agar $(1.5 \% \mathrm{w} / \mathrm{v})$ medium at $30^{\circ} \mathrm{C}$. Pseudomonas mutants and complemented mutants were maintained on similar plates containing the appropriate antibiotic. For all growth and proteomics experiments cultures were grown in an adapted Minimal A medium ${ }^{36}$ using Na-Succinate $(20 \mathrm{mM})$ as the sole carbon source and, where applicable, $10 \mathrm{mM} \mathrm{NH}_{4} \mathrm{Cl}$ was added as the sole $\mathrm{N}$ source. $2 \mathrm{AEP}$ and $\mathrm{KH}_{2} \mathrm{PO}_{4}$ were added to a final concentration of 100 $\mu \mathrm{M}$ or $1.5 \mathrm{mM}$ as specified in the text and figure legends. Pseudomonas strains were precultured in minimal medium A containing $100 \mu \mathrm{M}$ Pi and $1.5 \mathrm{mM} \mathrm{NH}_{4} \mathrm{Cl}$ to ensure adequate growth while minimising the potential for carryover of residual nutrients into experimental cultures. Co-culture experiments were carried out according to the protocol described in ${ }^{60}$. Culture experiments were performed using a FLUOStar Omega 96-well plate reader using Sarstedt 96-well plates incubated at $30^{\circ} \mathrm{C}$, shaking at $200 \mathrm{rpm}$. For $2 \mathrm{AEP}$ as $\mathrm{N}$ source proteomics, S. stellulata was grown in modified defined marine ammonium mineral salt (MAMS) media, lacking ammonium, and where HEPES replaced the phosphate buffer ${ }^{61}$. For all other growth and proteomics experiments these marine bacteria were grown in Sea Salts media ${ }^{62}$, where HEPES replaced the phosphate buffer.

\section{Generation and complementation of Pseudomonas mutants}

Mutants were generated and complemented via the protocols outlined in ${ }^{36,60}$. A full list of strains, plasmids, and primers used in this study is presented in Table S4. Briefly, regions of genomic DNA at the $5^{\prime}$ and $3^{\prime}$ end of each deletion target were amplified, along with in some cases the gentamicin resistance cassette from $\mathrm{p} 34 \mathrm{~S}-\mathrm{Gm}^{63}$. Other mutants were 
constructed to be marker-less, and so lacked this resistance cassette. DNA fragments were ligated into linearised pk18mobsacB ${ }^{64}$ using the HiFi DNA Assembly Kit (New England Biolabs, Hitchin, UK) according to the manufacturer's instructions. For the construction of plasmids for complementation, genes and their corresponding promoters were cloned into linearised pBBR1McS-km again using the HiFi DNA Assembly Kit.

Plasmids were subsequently electroporated into Escherichia coli S17.1 and mobilized into Pseudomonas by conjugation. Transconjugants were selected via gentamicin $\left(50 \mu \mathrm{g} \mathrm{ml}^{-1}\right)$ or kanamycin $\left(50 \mathrm{\mu g} \mathrm{ml}^{-1}\right)$ selection and chloramphenicol $\left(10 \mu \mathrm{g} \mathrm{ml}^{-1}\right)$ counter-selection. Single plating on LB containing either gentamicin or no antibiotic, and $10 \%(\mathrm{w} / \mathrm{v})$ sucrose. Pellets were resuspended in $500 \mu \mathrm{l} 200 \mathrm{mM} \mathrm{MgCl}, 50 \mathrm{mM}$ Tris- $\mathrm{HCl}, \mathrm{pH} 7.6$ and incubated for 
room temperature for 15 mins, then centrifuged at $8000 \times \mathrm{g}$ for 10 mins at $4^{\circ} \mathrm{C}$. Pellets were washed in $1 \mathrm{ml} \mathrm{50mM} \mathrm{Tris-} \mathrm{HCl}, \mathrm{pH} 7.6$, and again centrifuged at $8000 \times \mathrm{g}$ for 10 mins at $4^{\circ} \mathrm{C}$. Pellets were resuspended in $0.5 \mathrm{ml} 50 \mathrm{mM}$ Tris- $\mathrm{HCl}, \mathrm{pH} 7.6$, and sonicated for $30 \mathrm{~s}$ twice, on ice. The solution was centrifuged at $2000 \times \mathrm{g}$ for $15 \mathrm{mins}$ at $4^{\circ} \mathrm{C}$, and supernatants were then ultracentrifuged at $120000 \times \mathrm{g}$ for $45 \mathrm{mins}$ at $4^{\circ} \mathrm{C}$. Following this, the supernatant was discarded and the pellet resuspended in 50 $\mathrm{Ll}$ LDS buffer (Expedeon) prior to loading $20 \mu$ l onto a $4-20 \%$ Bis-Tris SDS precast gel (Expedeon). Gel sections were de-stained with $50 \mathrm{mM}$ ammonium bicarbonate in $50 \%$ ethanol, dehydrated with $100 \%$ ethanol, reduced and alkylated with Tris-2-carboxyethylphosphine (TCEP) and iodoacetamide (IAA), washed with $50 \mathrm{mM}$ ammonium bicarbonate in $50 \%$ ethanol and dehydrated with $100 \%$ ethanol prior to overnight digestion with trypsin. Peptides were extracted and analysed using an Orbitrap Fusion Ultimate 3000 RSLCNano System (Thermo Scientific) in electrospray ionization mode at the Warwick Proteomics Research Technology Platform.

Resulting MS/MS files were searched against the relevant protein sequence database (P. putida BIRD-1, NC_017530.1, S. stellulata, GCF_000423715.1) using MaxQuant ${ }^{65}$ with default settings and quantification was achieved using Label Free Quantification (LFQ). The proteomics analysis software Perseus $(1.6 .12)^{66}$ was used to identify differentially expressed proteins based on LFQ values, using a False Discovery Rate (FDR) of 0.01 . Identified proteins were retained if they were present in at least two biological replicates within a treatment. Missing (N/A) values were imputed from a normal distribution using the default parameters. 0.1 , or ANOVA, where appropriate. 
'Customized Homolog Display' search tool. Strains containing homologs were identified (cutoff values: $\mathrm{e}^{-70}, \mathrm{~min}$. identity $\left.40 \%\right)$, preferentially from type strains. In addition, representative strains from soil and marine environments were added to this list (see Table S2). Protein sequences were aligned using ClustalOmega ${ }^{67}$ and profile Hidden Markov Models (pHMMs) were constructed from these sequences using the hmmbuild function of hmmer 3.3 (http://hmmer.org) ${ }^{68}$. The previously characterised Escherichia coli $\mathrm{K}-12 \mathrm{PhnD}^{69}$ and the SAR11 clade isolate Pelagibacter sp. HTCC7211 PhnD ${ }^{21}$ showed surprisingly low sequence homology (BLAST \%ID 28.46\%, query coverage 76\%, e-value 2e-25). We therefore developed two pHMMS for PhnD to reflect this. There was no overlap in environmental sequences retrieved from each search using either hmm model. Therefore, abundance counts for each PhnD form were combined together as a collective PhnD group. These pHMMs were used to search the TARA ocean metagenome (OM-RGC_v2_metaG) and metatranscriptome (OMRGC_v2_metaT) via the Ocean Gene Atlas web interface ${ }^{44}$, using a stringency of $1 \mathrm{E}^{-80}$. Sequence abundances were expressed as average percentage of genomes containing a copy by dividing the percentage of total mapped reads by the median abundance (as a percentage of total mapped reads) of 10 single-copy marker genes ${ }^{70}$ for both MG and MT. The pHMMs were used to search the soil MG via hmmsearch ${ }^{68}$ using the same stringency as above. Similarly, abundances were calculated as average percentage of genomes containing a copy as above. parameters: -m TEST -bb 1000 -alrt 1000. Evolutionary relationships were inferred by maximum-likelihood analysis, and visualised using the Interactive Tree of Life (iTOL) v5.6.3 online platform (https://itol.embl.de/) $)^{72}$ 
399 Unless specified above, all statistical analysis was performed using R (version 4.02) ${ }^{73}$, within 400 the RStudio programme (version 1.3$)^{74}$.

401

\section{Acknowledgements}

402

403

404

405

406

407

408

409

410

411

412

413

414

415

416

417

418

419

420

421

422

423

424

425

426

427

428

429

430

We thank the Warwick Proteomics Research Facility, namely Dr. Cleidiane Zampronio for her assistance in generating and processing the mass-spectrometry data. This study was funded by the Biotechnology and Biological Sciences Research Council (BBSRC) under project codes BB/L026074/1 and BB/T009152/1 linked to The Soil and Rhizosphere Interactions for Sustainable Agri-ecosystems (SARISA) programme and a Discovery Fellowship (IL), respectively.

\section{References}

1 Villarreal-Chiu, J. F., Quinn, J. P. \& McGrath, J. W. The genes and enzymes of phosphonate metabolism by bacteria, and their distribution in the marine environment. Front Microbio/ 3, 19, doi:10.3389/fmicb.2012.00019 (2012).

2 Mukhamedova, K. S. \& Glushenkova, A. I. Natural Phosphonolipids. Chem Natural Compounds 36, 329-341, doi:10.1023/A:1002804409503 (2000).

$3 \mathrm{Yu}, \mathrm{X}$. et al. Diversity and abundance of phosphonate biosynthetic genes in nature. Proc Natl Acad Sci U S A 110, 20759-20764, doi:10.1073/pnas.1315107110 (2013).

4 Ju, K.-S., Doroghazi, J. R. \& Metcalf, W. W. Genomics-enabled discovery of phosphonate natural products and their biosynthetic pathways. J Industrial Microbiol \& Biotechnol 41, 345-356, doi:10.1007/s10295-013-1375-2 (2014).

5 Peck, S. C. \& van der Donk, W. A. Phosphonate biosynthesis and catabolism: a treasure trove of unusual enzymology. Curr Opin Chem Biol 17, 580-588, doi:https://doi.org/10.1016/j.cbpa.2013.06.018 (2013).

6 Metcalf, W. W. et al. Synthesis of methylphosphonic acid by marine microbes: a source for methane in the aerobic ocean. Science 337, 1104-1107, doi:10.1126/science.1219875 (2012).

7 Born, D. A. et al. Structural basis for methylphosphonate biosynthesis. Science 358, 1336, doi:10.1126/science.aao3435 (2017).

$8 \quad$ Hildebrand, R. The Role of Phosphonates in Living Systems. (CRC Press, 1983).

9 Van Mooy, B. A. S. et al. Major role of planktonic phosphate reduction in the marine phosphorus redox cycle. Science 348, 783, doi:10.1126/science.aaa8181 (2015). 
$43110 \quad$ Kolowith, L. C., Ingall, E. D. \& Benner, R. Composition and cycling of marine organic phosphorus. Limnol Oceanogr 46, 309-320, doi:10.4319/lo.2001.46.2.0309 (2001).

11 Clark, L. L., Ingall, E. D. \& Benner, R. Marine phosphorus is selectively remineralized. Nature 393, 426-426, doi:10.1038/30881 (1998).

12 Turner, B. L., Baxter, R., Mahieu, N., Sjögersten, S. \& Whitton, B. A. Phosphorus compounds in subarctic Fennoscandian soils at the mountain birch (Betula pubescens)-tundra ecotone. Soil Biol Biochem 36, 815-823, doi:https://doi.org/10.1016/j.soilbio.2004.01.011 (2004). Tate, K. R. \& Newman, R. H. Phosphorus fractions of a climosequence of soils in New Zealand tussock grassland. Soil Biol Biochem 14, 191-196, doi:https://doi.org/10.1016/00380717(82)90022-0 (1982).

14 Cade-Menun, B. J., Navaratnam, J. A. \& Walbridge, M. R. Characterizing dissolved and particulate phosphorus in water with 31P nuclear magnetic resonance spectroscopy. Environ Sci Technol 40, 7874-7880, doi:10.1021/es061843e (2006). Clark, L. L., Ingall, E. D. \& Benner, R. Marine organic phosphorus cycling; novel insights from nuclear magnetic resonance. American J Sci 299, 724-737 (1999).

16 Repeta, D. J. et al. Marine methane paradox explained by bacterial degradation of dissolved organic matter. Nature Geosci 9, 884-887, doi:10.1038/ngeo2837 (2016). Sosa, O. A. et al. Phosphonate cycling supports methane and ethylene supersaturation in the phosphate-depleted western North Atlantic Ocean. Limnol Oceanogr 65, 2443-2459, doi:10.1002/Ino.11463 (2020).

18 Dyhrman, S. T., Benitez-Nelson, C. R., Orchard, E. D., Haley, S. T. \& Pellechia, P. J. A microbial source of phosphonates in oligotrophic marine systems. Nature Geoscience 2, 696-699, doi:10.1038/ngeo639 (2009).

19 Acker, M. et al. Phosphonate production by marine microbes: exploring new sources and potential function. bioRxiv, 2020.2011.2004.368217, doi:10.1101/2020.11.04.368217 (2020).

20 Sosa, O. A., Repeta, D. J., DeLong, E. F., Ashkezari, M. D. \& Karl, D. M. Phosphate-limited ocean regions select for bacterial populations enriched in the carbon-phosphorus lyase pathway for phosphonate degradation. Environ Microbiol 21, 2402-2414, doi:10.1111/14622920.14628 (2019).

21 Carini, P., White, A. E., Campbell, E. O. \& Giovannoni, S. J. Methane production by phosphate-starved SAR11 chemoheterotrophic marine bacteria. Nature Comms 5, 4346, doi:10.1038/ncomms5346 (2014).

22 Chin, J. P., Quinn, J. P. \& McGrath, J. W. Phosphate insensitive aminophosphonate mineralisation within oceanic nutrient cycles. ISME J 12, 973-980, doi:10.1038/s41396-0170031-7 (2018).

23 Ternan, N. G. \& Quinn, J. P. Phosphate starvation-independent 2-aminoethylphosphonic acid biodegradation in a newly isolated strain of Pseudomonas putida, NG2. Syst Appl Microbiol 21, 346-352, doi:10.1016/S0723-2020(98)80043-X (1998).

24 White, A. K. \& Metcalf, W. W. Microbial metabolism of reduced phosphorus compounds. Annu Rev Microbiol 61, 379-400, doi:10.1146/annurev.micro.61.080706.093357 (2007).

25 Martinez, A., Tyson, G. W. \& Delong, E. F. Widespread known and novel phosphonate utilization pathways in marine bacteria revealed by functional screening and metagenomic analyses. Environ Microbiol 12, 222-238, doi:10.1111/j.1462-2920.2009.02062.x (2010).

26 Wanner, B. L. Molecular genetics of carbon-phosphorus bond cleavage in bacteria. Biodegradation 5, 175-184 (1994).

27 Kononova, S. V. \& Nesmeyanova, M. A. Phosphonates and their degradation by microorganisms. Biochemistry (Mosc) 67, 184-195 (2002).

28 Sowell, S. M. et al. Transport functions dominate the SAR11 metaproteome at low-nutrient extremes in the Sargasso Sea. ISME J 3, 93-105, doi:http://www.nature.com/ismej/journal/v3/n1/suppinfo/ismej200883s1.html (2008). 
29 Alicea, I. et al. Structure of the Escherichia coli phosphonate binding protein PhnD and rationally optimized phosphonate biosensors. J Mol Biol 414, 356-369, doi:10.1016/j.jmb.2011.09.047 (2011).

30 Rizk, S. S., Cuneo, M. J. \& Hellinga, H. W. Identification of cognate ligands for the Escherichia coli phnD protein product and engineering of a reagentless fluorescent biosensor for phosphonates. Protein Sci 15, 1745-1751, doi:10.1110/ps.062135206 (2006).

31 Jiang, W., Metcalf, W. W., Lee, K. S. \& Wanner, B. L. Molecular cloning, mapping, and regulation of Pho regulon genes for phosphonate breakdown by the phosphonatase pathway of Salmonella typhimurium LT2. J Bacteriol 177, 6411, doi:10.1128/jb.177.22.64116421.1995 (1995).

$32 \mathrm{Kim}, \mathrm{A}$. D. et al. The 2-aminoethylphosphonate-specific transaminase of the 2aminoethylphosphonate degradation pathway. J Bacteriol 184, 4134, doi:10.1128/JB.184.15.4134-4140.2002 (2002).

33 Ottesen, E. A. et al. Pattern and synchrony of gene expression among sympatric marine microbial populations. Proc Natl Acad Sci USA 110, E488-E497, doi:10.1073/pnas.1222099110 (2013).

34 Lidbury, I., Murrell, J. C. \& Chen, Y. Trimethylamine N-oxide metabolism by abundant marine heterotrophic bacteria. Proc Natl Acad Sci USA 111, 2710-2715, doi:10.1073/pnas.1317834111 (2014).

35 Mauchline, T. H. et al. Mapping the Sinorhizobium meliloti 1021 solute-binding proteindependent transportome. Proc Natl Acad Sci 103, 17933-17938, doi:10.1073/pnas.0606673103 (2006).

36 Lidbury, I. D. et al. Comparative genomic, proteomic and exoproteomic analyses of three Pseudomonas strains reveals novel insights into the phosphorus scavenging capabilities of soil bacteria. Environ Microbiol 18, 3535-3549, doi:10.1111/1462-2920.13390 (2016).

37 Lemieux, M. J., Huang, Y. \& Wang, d. N. Crystal structure and mechanism of GlpT, the glycerol-3-phosphate transporter from E. coli. J Electron Microsc 54 Suppl 1, i43-46, doi:10.1093/jmicro/54.suppl_1.i43 (2005).

38 Elvin, C. M., Hardy, C. M. \& Rosenberg, H. Pi exchange mediated by the GlpT-dependent snglycerol-3-phosphate transport system in Escherichia coli. J Bacteriol 161, 1054-1058 (1985).

39 Enkavi, G. \& Tajkhorshid, E. Simulation of spontaneous substrate binding revealing the binding pathway and mechanism and initial conformational response of GlpT. Biochemistry 49, 1105-1114, doi:10.1021/bi901412a (2010).

40 Law, C. J. et al. Salt-bridge dynamics control substrate-induced conformational change in the membrane transporter GlpT. J Mol Biol 378, 828-839, doi:https://doi.org/10.1016/j.jmb.2008.03.029 (2008).

41 Law, C. J., Enkavi, G., Wang, D.-N. \& Tajkhorshid, E. Structural basis of substrate selectivity in the glycerol-3-phosphate: phosphate antiporter GlpT. Biophysical J 97, 1346-1353, doi:10.1016/j.bpj.2009.06.026 (2009).

42 Moradi, M., Enkavi, G. \& Tajkhorshid, E. Atomic-level characterization of transport cycle thermodynamics in the glycerol-3-phosphate:phosphate antiporter. Nature Comms 6, 8393, doi:10.1038/ncomms9393 (2015).

43 Borisova, S. A. et al. Genetic and biochemical characterization of a pathway for the degradation of 2-aminoethylphosphonate in Sinorhizobium meliloti 1021. J Biol Chem 286, 22283-22290, doi:10.1074/jbc.M111.237735 (2011).

44 Villar, E. et al. The Ocean Gene Atlas: exploring the biogeography of plankton genes online. Nucleic Acids Res 46, W289-W295, doi:10.1093/nar/gky376 (2018).

45 Smith, A. F. et al. Elucidation of glutamine lipid biosynthesis in marine bacteria reveals its importance under phosphorus deplete growth in Rhodobacteraceae. ISME J 13, 39-49, doi:10.1038/s41396-018-0249-z (2019). 
46 Chin, J. P., McGrath, J. W. \& Quinn, J. P. Microbial transformations in phosphonate biosynthesis and catabolism, and their importance in nutrient cycling. Curr Opin Chem Biol 31, 50-57, doi:10.1016/j.cbpa.2016.01.010 (2016).

47 White, A. K. \& Metcalf, W. W. Two C-P lyase operons in Pseudomonas stutzeri and their roles in the oxidation of phosphonates, phosphite, and hypophosphite. J Bacteriol 186, 47304739, doi:10.1128/JB.186.14.4730-4739.2004 (2004).

48 Ermakova, I. T. et al. Organophosphonates utilization by soil strains of Ochrobactrum anthropi and Achromobacter sp. Arch Microbiol 199, 665-675, doi:10.1007/s00203-0171343-8 (2017).

49 Hartley, L. E., Kaakoush, N. O., Ford, J. L., Korolik, V. \& Mendz, G. L. Characterisation of Campylobacter jejuni genes potentially involved in phosphonate degradation. Gut Pathog $\mathbf{1}$, 13, doi:10.1186/1757-4749-1-13 (2009).

50 Imazu, K. et al. Enhanced utilization of phosphonate and phosphite by Klebsiella aerogenes. Appl Environ Microbiol 64, 3754-3758 (1998).

51 Mendz, G. L., Mégraud, F. \& Korolik, V. Phosphonate catabolism by Campylobacter spp. Arch Microbiol 183, 113-120, doi:10.1007/s00203-004-0752-7 (2005).

52 Metcalf, W. W. \& Wanner, B. L. Evidence for a fourteen-gene, phnC to phnP locus for phosphonate metabolism in Escherichia coli. Gene 129, 27-32, doi:10.1016/03781119(93)90692-v (1993).

53 Hultman, J. et al. Multi-omics of permafrost, active layer and thermokarst bog soil microbiomes. Nature 521, 208-212, doi:10.1038/nature14238 (2015).

54 Frischkorn, K. R. et al. Trichodesmium physiological ecology and phosphate reduction in the western tropical South Pacific. Biogeosciences 15, 5761-5778, doi:10.5194/bg-15-5761-2018 (2018).

55 Young, C. L. \& Ingall, E. D. Marine dissolved organic phosphorus composition: insights from samples recovered using combined electrodialysis/ reverse osmosis. Aquatic Geochem 16, 563-574, doi:10.1007/s10498-009-9087-y (2010).

56 Benitez-Nelson, C. R., O'Neill, L., Kolowith, L. C., Pellechia, P. \& Thunell, R. Phosphonates and particulate organic phosphorus cycling in an anoxic marine basin. Limnol Oceanogr 49, $1593-$ 1604, doi:10.4319/lo.2004.49.5.1593 (2004).

57 Lidbury, I. D. E. A., Murrell, J. C. \& Chen, Y. Trimethylamine and trimethylamine N-oxide are supplementary energy sources for a marine heterotrophic bacterium: implications for marine carbon and nitrogen cycling. ISME J 9, 760-769, doi:10.1038/ismej.2014.149 (2015).

58 Dyhrman, S. T. et al. Phosphonate utilization by the globally important marine diazotroph Trichodesmium. Nature 439, 68-71, doi:10.1038/nature04203 (2006).

59 Karl, D. M. et al. Aerobic production of methane in the sea. Nature Geosci 1, 473-478, doi:10.1038/ngeo234 (2008).

60 Lidbury, I. D. E. A. et al. Identification of extracellular glycerophosphodiesterases in Pseudomonas and their role in soil organic phosphorus remineralisation. Sci Rep 7, 2179, doi:10.1038/s41598-017-02327-6 (2017).

61 Lidbury, I., Kimberley, G., Scanlan, D. J., Murrell, J. C. \& Chen, Y. Comparative genomics and mutagenesis analyses of choline metabolism in the marine Roseobacter clade. Environ Microbiol 17, 5048-5062 (2015).

62 Chen, Y. Comparative genomics of methylated amine utilization by marine Roseobacter clade bacteria and development of functional gene markers (tmm, gmaS). Environ Microbiol 14, 2308-2322, doi:10.1111/j.1462-2920.2012.02765.x (2012).

63 Dennis, J. J. \& Zylstra, G. J. Plasposons: modular self-cloning minitransposon derivatives for rapid genetic analysis of gram-negative bacterial genomes. Appl Environ Microbiol 64, 27102715 (1998).

64 Schäfer, A. et al. Small mobilizable multi-purpose cloning vectors derived from the Escherichia coli plasmids pK18 and pK19: selection of defined deletions in the chromosome 

(1994).

58465 Tyanova, S., Temu, T. \& Cox, J. The MaxQuant computational platform for mass spectrometry-based shotgun proteomics. Nature Protocols 11, 2301-2319, doi:10.1038/nprot.2016.136 (2016).

66 Tyanova, S. et al. The Perseus computational platform for comprehensive analysis of (prote)omics data. Nature Methods 13, 731-740, doi:10.1038/nmeth.3901 (2016).

67 Madeira, F. et al. The EMBL-EBI search and sequence analysis tools APIs in 2019. Nucleic Acids Res 47, W636-W641, doi:10.1093/nar/gkz268 (2019).

68 Finn, R. D., Clements, J. \& Eddy, S. R. HMMER web server: interactive sequence similarity searching. Nucleic Acids Res 39, W29-W37, doi:10.1093/nar/gkr367 (2011).

69 Wackett, L. P., Wanner, B. L., Venditti, C. P. \& Walsh, C. T. Involvement of the phosphate regulon and the psiD locus in carbon-phosphorus lyase activity of Escherichia coli K-12. J Bacteriol 169, 1753-1756, doi:10.1128/jb.169.4.1753-1756.1987 (1987).

70 Milanese, A. et al. Microbial abundance, activity and population genomic profiling with mOTUs2. Nature Comms 10, 1014, doi:10.1038/s41467-019-08844-4 (2019).

71 Minh, B. Q. et al. IQ-TREE 2: New models and efficient methods for phylogenetic inference in the genomic era. Mol Biol Evol 37, 1530-1534, doi:10.1093/molbev/msaa015 (2020).

72 Letunic, I. \& Bork, P. Interactive Tree Of Life (iTOL) v4: recent updates and new developments. Nucleic Acids Res 47, W256-W259, doi:10.1093/nar/gkz239 (2019).

73 (2020)., R. C. T. R: A language and environment for statistical computing. R Foundation for Statistical Computing, Vienna, Austria., <https://www.R-project.org/> (2020).

605 

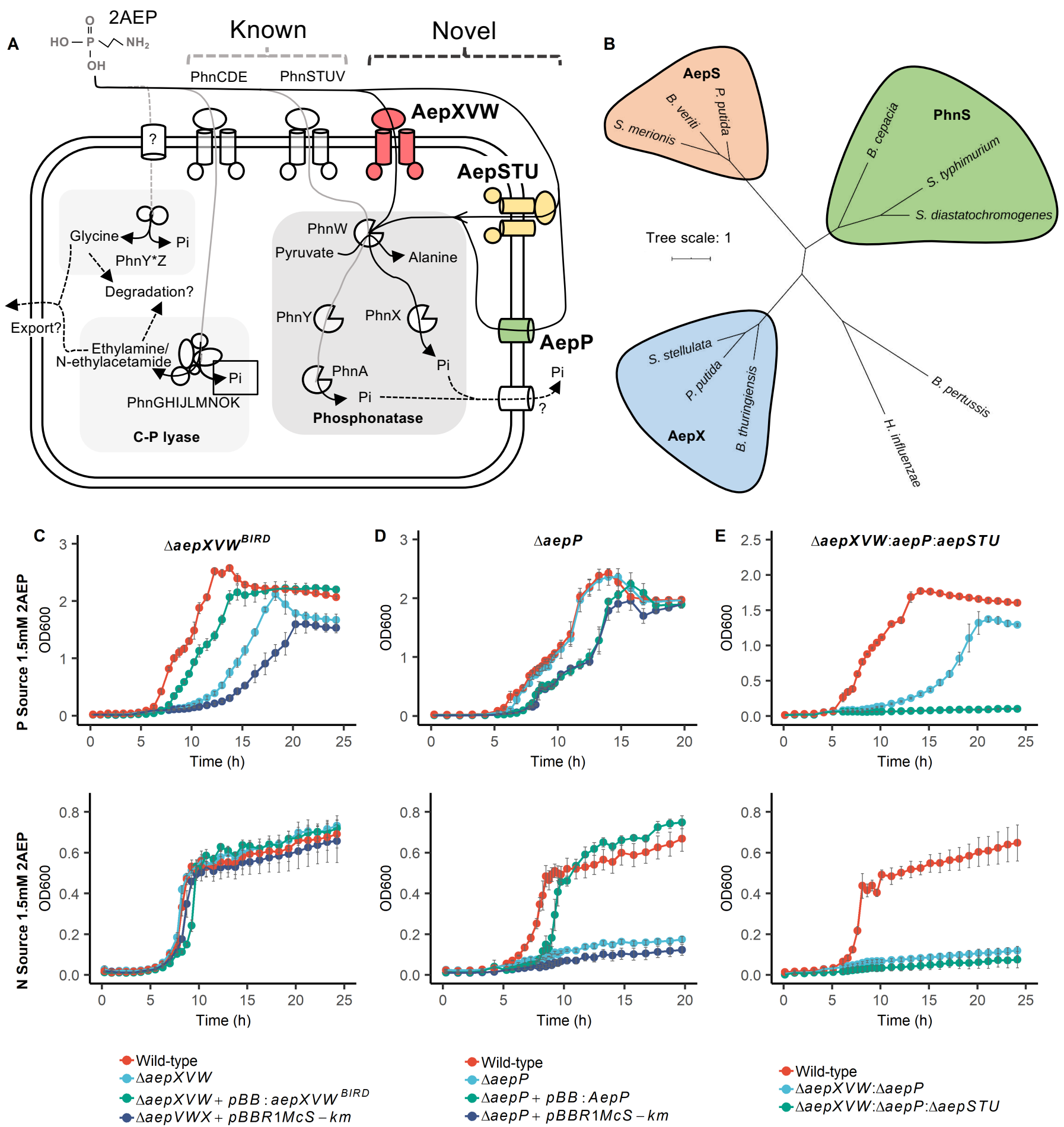

$$
\begin{aligned}
& \text { - Wild-type } \\
& \text { - } \Delta \text { aepXVW: } \Delta a e p P \\
& \text { - } \Delta \text { aepXVW: } \triangle \operatorname{aep} P: \Delta a e p S T U
\end{aligned}
$$

Figure 1. 2AEP transport and catabolism in P. putida BIRD-1. (A) Schematic representation of novel (highlighted in bold and coloured) routes for 2AEP transport, together with existing characterised and putative 2AEP transport routes. Each catabolic system for degradation is highlighted and includes i) the phosphonatase system comprising a 2AEP-pyruvate transaminase $(\mathrm{PhnW})$ and either a phosphonoacetaldehyde hydrolase $(\mathrm{PhnX})^{74,75}$ or a $\mathrm{NAD}^{+}$-dependent phosphonoacetaldehyde dehydrogenase (PhnY) and a phosphonoacetate hydrolase ( $\mathrm{PhnA})^{43}$, and ii) the PhnY*Z system comprising phosphohydrolase ( $\mathrm{PhnZ})^{21,76}$ and a 2-oxoglutarate dioxygenase $\left(\mathrm{PhnY}^{*}\right)^{77}$. In addition, the promiscuous multi subunit enzyme C-P lyase (PhnGHIJKLMN) can also act on 2AEP78, as well as akylphosphonates ${ }^{14,15,23}$. Pathways found in BIRD-1 are represented by black lines, pathways absent from BIRD-1 are shaded grey. Characterised pathways are shown with solid lines, uncharacterised pathways are shown with dashed lines. Transporters found in BIRD-1 are red if Pisensitive, green if Pi-insensitive, and yellow if constitutive. Unknown mechanisms are denoted by a '?'. (B) Phylogenetic tree of AepX, PhnS, and AepS, using the characterised $\mathrm{Fe}^{3+}$ substrate binding protein $\mathrm{FBPa}$ from Haemophilus influenzae and Bordetella pertussis as an outgroup. P. putida = Pseudomonas putida BIRD-1, S. stellulata = Stappia stellulata, B. cepacia $=$ Burkholderia cepacia, $B$. vireti = Bacillus veriti, S. merionis = Streptococcus merionis, S. typhimurium = Salmonella typhimurium, S. diastatochromogenes = Streptomyces diastatochromogenes, B. thuringiensis = Bacillus thuringiensis. (C) Growth $(\mathrm{n}=4)$ of $P$. putida BIRD-1 wild type, $\triangle a e p X V W$, and the complemented mutant. (D), $\triangle a e p P$ and the complemented mutant, and (E), the 2AEP null mutant, $\triangle$ aepXVW::aepP::aepSTU. All strains used 2AEP as a sole P (top panel) or $\mathrm{N}$ (bottom panel) source. Error bars denote standard deviation of the mean. 
A

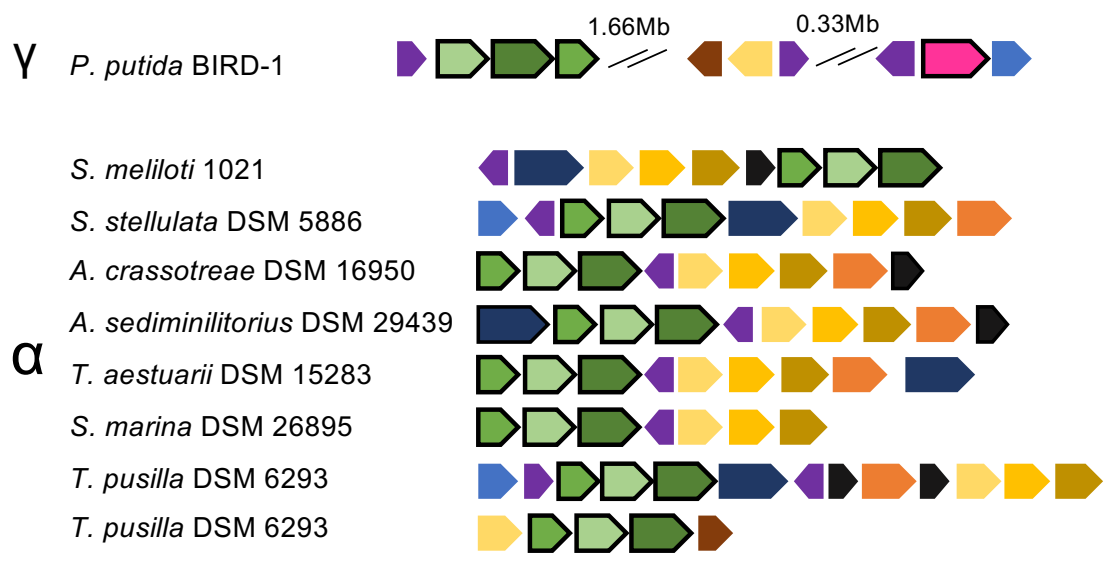

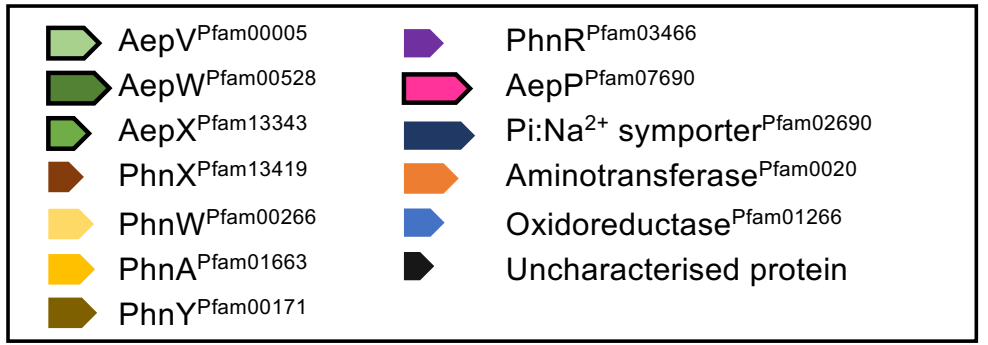

B

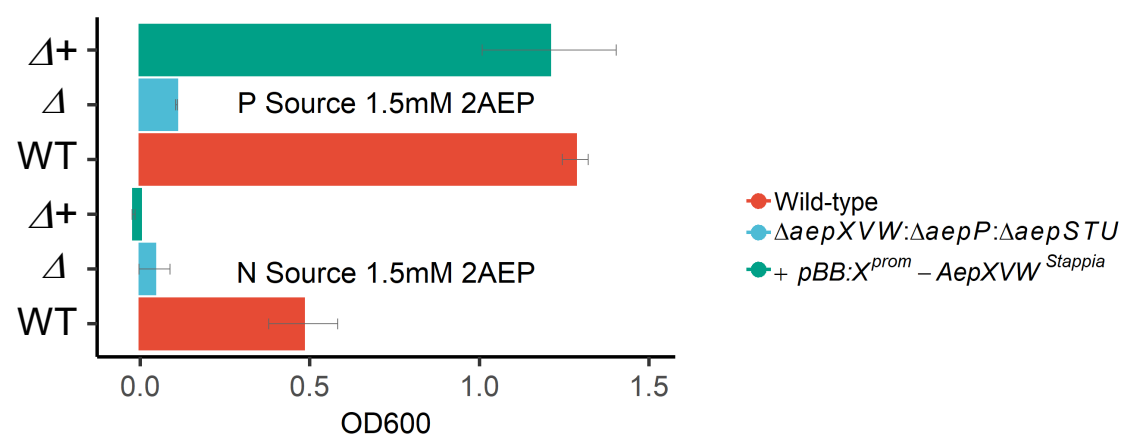

Figure 2. Distribution and functional characterisation of AepXVW in marine bacteria. (A) Genetic neighbourhoods of aepXVW within marine Alpha- and terrestrial Gamma-proteobacteria. Strains shown are Pseudomonas putida BIRD-1, Sinorhizobium meliloti 1021, Stappia stellulata DSM 5886, Aliiroseovarius crassostreae DSM 16950, Aliiroseovarius sediminilitoris DSM 29439, Thalassobius aestuarii DSM 15283, and Shimia marina DSM 26895. ORFs separated on the genome are indicated by breaks with the corresponding gap given in megabases (Mb). (B) Growth of the $P$. putida BIRD-1 triple 2AEP transporter mutant ( $\triangle$ aepXVW:aepP:aepSTU:gm) complemented with aepXVWStappia concatenated with the promoter region from aepXVWBIRD on $2 A E P$ as either a sole $N(60 \mathrm{~h})$ or $\mathrm{P}(48 \mathrm{~h})$ source. Data represents the mean of triplicates cultures. Error bars denote standard deviation. 
A

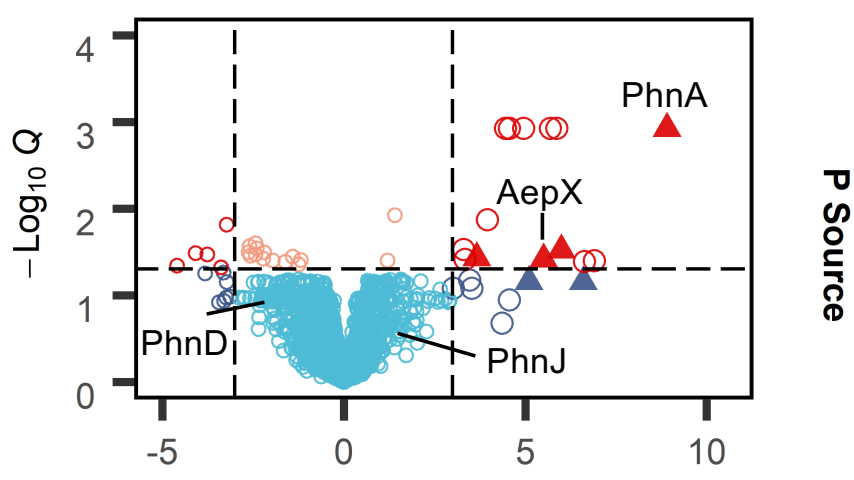

B

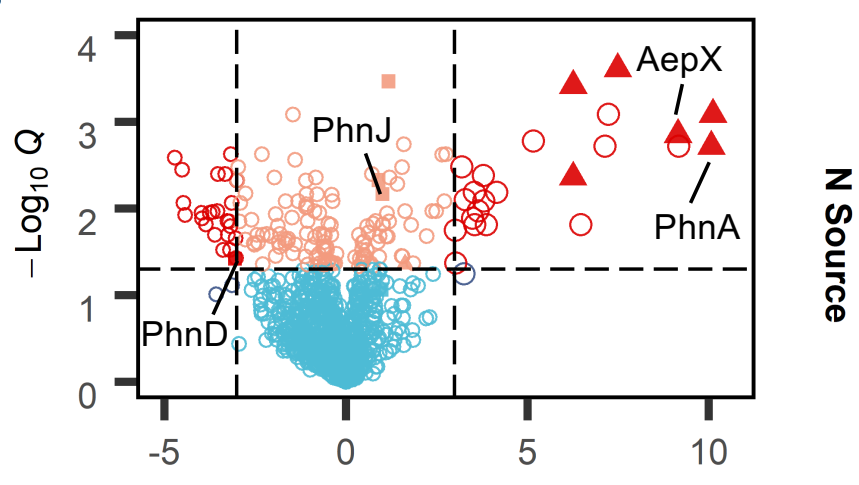

$\log _{2}$ fold change

FC cutoff, 3, q-value cutoff, 0.05

Figure 3. Proteomic analysis of 2AEP-grown S. stellulata cells. Whole-cell protein expression profiles $(n=3)$ for $S$. stellulata grown using either $\mathrm{Pi}$ or $2 \mathrm{AEP}$ as sole $\mathrm{P}$ source (A) or $\mathrm{NH}_{4}$ or 2AEP as the sole $\mathrm{N}$ source (B). Fold change represents the difference in Log2 LFQ values between each treatment and the statistical value on the $Y$ axis is generated from $Q$ values (FDR corrected $P$ values). Members of the aepXVW-phnWAY operon are shown as triangles, members of the CP lyase operon are shown as squares, all other proteins are shown as open circles. Data plotted represents the mean of triplicate cultures. 


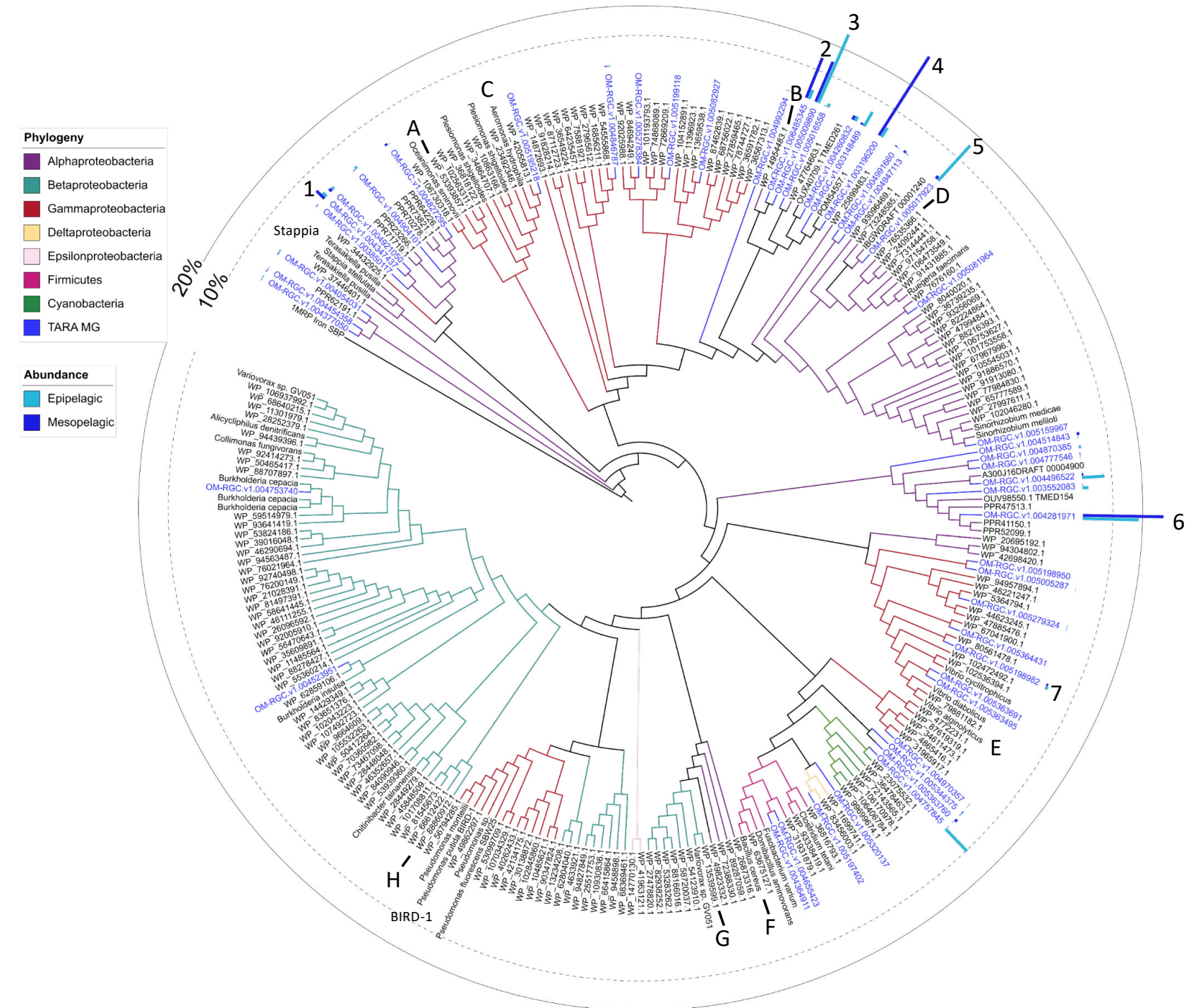

A) Vibrio nereis DSM 19584

B) Alphaproteobacterium HIMB59

C) Aeromonas hydrophila NF1

D) Roseovarius nanhaiticus DSM 29590

E) Vibrio alginolyticus ATCC 33787

F) Bacillus cereus ATCC 4342

G) Variovorax paradoxus EPS

H) Laribacter hongkongensis HLHK9

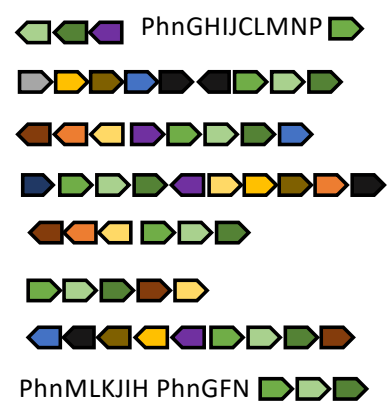

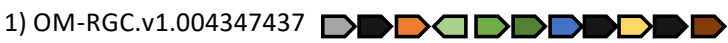

2) OM-RGC.v1.006485345 口ద口冋口

3) OM.RGC.v1. $005009890 \square \square \square \square \square \square$

4) OM-RGC.v1.003196200 $\square \square \square \square$

5) OM.RGC.v1. $005017923 \square \square \square \square \square \square \square \square$

6) OM-RGC.v1. $004281971 \square \square \square \square \square \square \square \square \square$

7) OM.RGC.v1. $005198982 \square \square \square \square$

\section{ORFs}

\begin{tabular}{|c|c|c|c|c|}
\hline $\begin{array}{l}\text { D AepVPfam00005 } \\
\text { DepWPfam00528 } \\
\text { D AepXPfam13343 }\end{array}$ & $\begin{array}{l}\text { PhnX Pfam13419 } \\
\text { PhnW'Pfam00266 } \\
\text { PhnAPfam01663 } \\
\text { D PhnYPfam00171 }\end{array}$ & $\begin{array}{l}\text { PhnR Pfam03466 } \\
\text { DepPPfam07690 } \\
\text { DepYPfam02690 } \\
\text { D AepZ } \\
\text { Pfam00202 }\end{array}$ & $\begin{array}{l}\square \text { Oxidoreductase } \text { Pfam } 01266 \\
\text { Uncharacterised protein } \\
\square \text { PHO4 PiTPfam01384 } \\
\square \text { Aldehyde dehydrogenase } \\
\text { Pfam00171 }\end{array}$ & $\begin{array}{l}\text { Alcohol dehydrogenase } \\
\text { Pfam00465 } \\
\text { Amidohydrolase Pfam07969 }\end{array}$ \\
\hline
\end{tabular}

Figure 4. Phylogenetic and genomic analyses of aepX in marine and terrestrial bacteria. Genetic neighbourhoods for selected aepX homologs are presented adjacent to trees. Numbers indicate environmental OTUs and letters indicate isolates or MAGs/SAGs. Tree topology and branch lengths were calculated by maximum likelihood using the $\mathrm{LG}+\mathrm{F}+\mathrm{I}+\mathrm{G} 4$ model of evolution for amino acid sequences based on 744 sites in IQ-TREE software 70 . A consensus tree was generated using 1000 bootstraps. Branches representing isolates or MAGs/SAGs are colour coded based on their phylogenetic affiliation (see legends). Branches and identifiers for representative environmental OTU sequences (clustered at 0.8 ) retrieved from the TARA Oceans database are highlighted blue. The outer ring denotes the relative abundance of environmental AepX OTUs using the same colour scheme; $10 \%$ (dashed line) and $20 \%$ (filled line) thresholds are shown for scale. S. stellulata DSM 5886 and P. putida BIRD-1 aepX are labelled. 

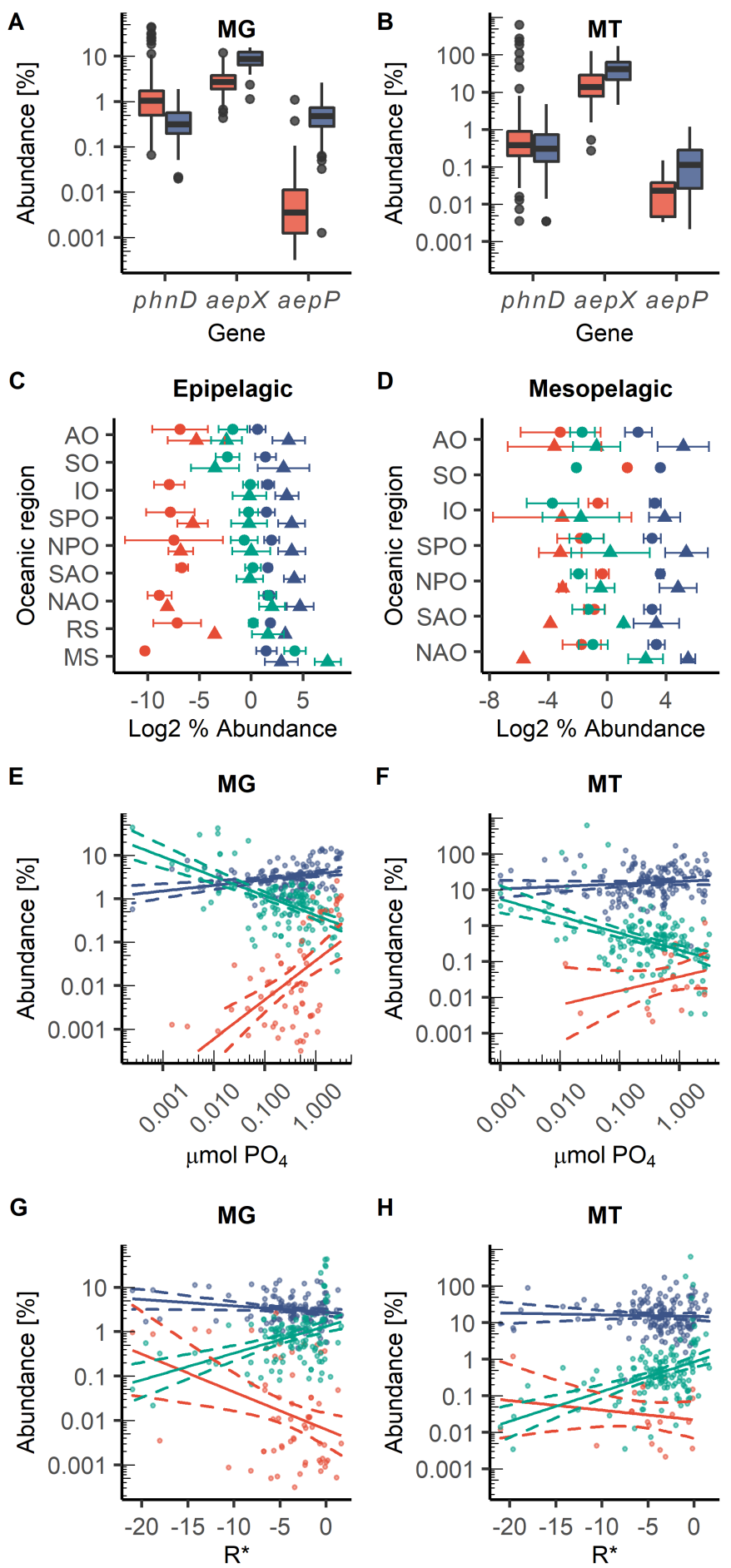

Figure 5. Distribution and transcriptional regulation of phosphonate transporter genes in the global ocean. Abundance of $p h n D$, aepX, aepP in marine epipelagic (red) and mesopelagic (blue) waters, split by metagenome (MG) (A), and metatranscriptome (MT) (B). Abundance (Log2 \% abundance related to single copy core genes) of $p h n D$, aepX, aepP in MG (circles) and MT (triangles) in epipelagic (C) and mesopelagic (D) waters, split by oceanic region. aepP (red), phnD (green), aepX (blue). AO = Arctic Ocean, SO = Southern Ocean, $1 O=$ Indian Ocean, SPO = South Pacific Ocean, NPO = North Pacific Ocean, SAO = South Atlantic Ocean, $\mathrm{NAO}=$ North Atlantic Ocean, $\mathrm{RS}=$ Red Sea, MS = Mediterranean Sea. The relationship between the standing stock Pi concentration and transporter abundance in the MG $(\mathrm{E}),\left(\operatorname{aep} X \mathrm{R}^{2}=0.098^{* * *}, p h n D \mathrm{R}^{2}=0.340^{* * *}\right.$, aepP $\mathrm{R}^{2}=0.291^{* * *}$ ) and $\mathrm{MT}(\mathrm{F})$, (aepX $\mathrm{R}^{2}=0.007^{\text {ns }}, p h n D \mathrm{R}^{2}=0.203^{* * *}$, aepP $\left.\mathrm{R}^{2}=0.058^{\text {ns }}\right)$. aepP (red), phnD (green), aepX (blue), $\mathrm{ns}=$ not significant, ${ }^{* * *}=\mathrm{p}<0.001$. The relationship between $\mathrm{R}^{*}$, a measure of $\mathrm{N}$ vs $\mathrm{P}$ limitation defined as the sum of standing stock nitrate plus nitrite concentration minus $16 \mathrm{x}$ standing stock $\mathrm{Pi}$ concentration, and transporter abundance in the MG $(\mathbf{G})\left(\right.$ aepX $\mathrm{R}^{2}=0.029^{*}, p h n D \mathrm{R}^{2}=0.168^{* * *}$, aepP $\mathrm{R}^{2}=$ $0.108^{* * *}$ ) and MT (H) (aepX $\mathrm{R}^{2}=-0.005^{\mathrm{ns}}$, phnD $\mathrm{R}^{2}=0.197^{* * *}$, aepP $\mathrm{R}^{2}=-0.014^{\mathrm{ns}}$ ). aepP (red), phnD (green), aepX (blue), ns $=$ not significant, ${ }^{*}=p<0.05,{ }^{* * *}=p<0.001$. 

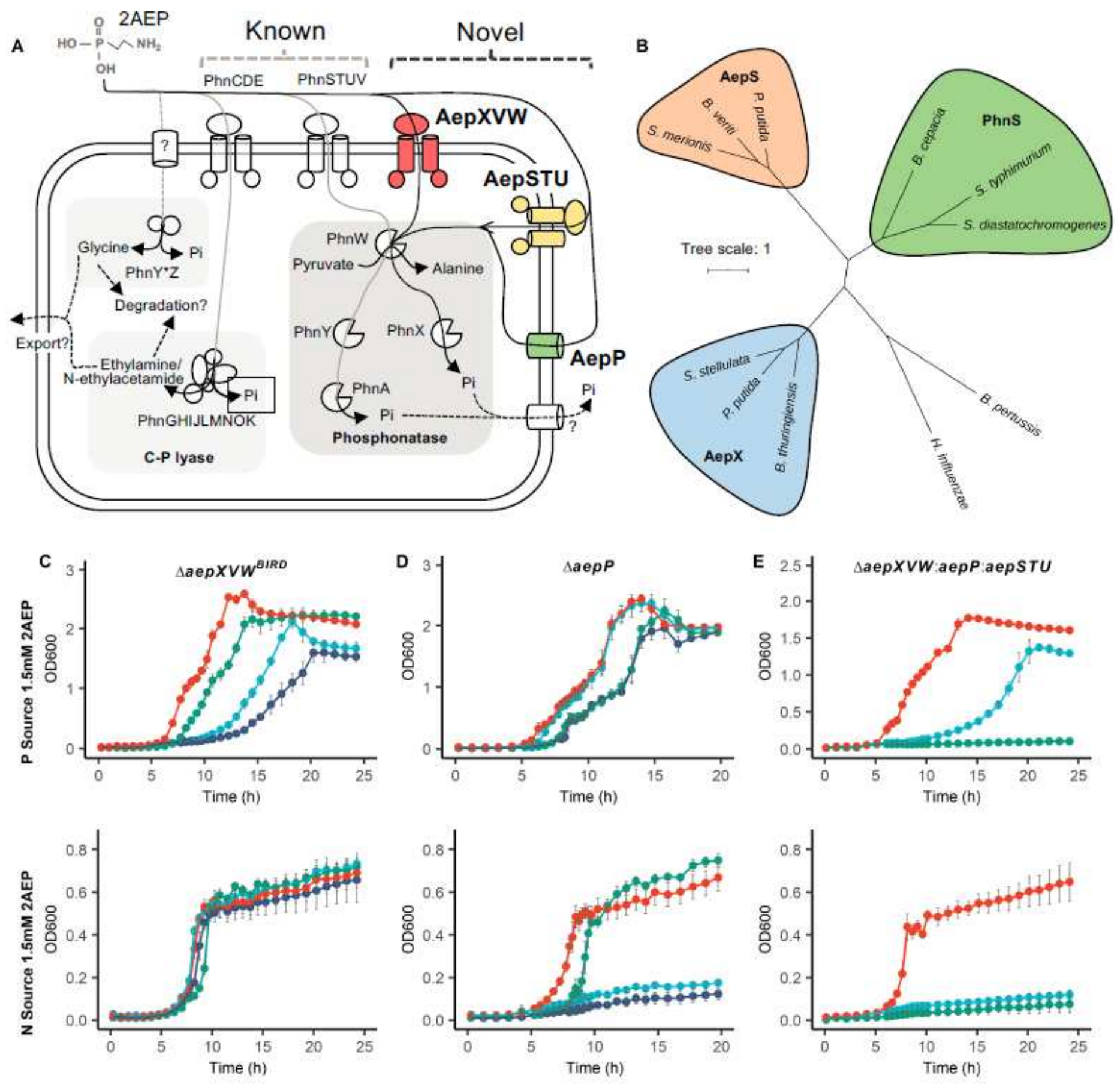

-Wid-type

- $\Delta a u p \times V W$

- $\operatorname{cae} p X V W+p B B: a e p \times V W W^{B / R D}$

- $\triangle a e p V W X+p B B R 1 M c S-k m$

- Wild-type

- $\Delta a e p P$

- $\triangle a e \rho P+p B B: A e p P$

- $\Delta a e \rho P+p B B R 1 M c S-k m$
- Wild-type

- $\Delta a e p X V W: \Delta a e p P$

- $\Delta a e p X V W: \Delta a e p P: \triangle a e p S T U$

\section{Figure 1}

2AEP transport and catabolism in P. putida BIRD-1. (A) Schematic representation of novel (highlighted in bold and coloured) routes for 2AEP transport, together with existing characterised and putative 2AEP transport routes. Each catabolic system for degradation is highlighted and includes i) the phosphonatase 
system comprising a 2AEP-pyruvate transaminase (PhnW) and either a phosphonoacetaldehyde hydrolase (PhnX)74,75 or a NAD+-dependent phosphonoacetaldehyde dehydrogenase (PhnY) and a phosphonoacetate hydrolase (PhnA)43, and ii) the PhnY*Z system comprising phosphohydrolase (PhnZ)21,76 and a 2-oxoglutarate dioxygenase (PhnY*)77. In addition, the promiscuous multi subunit enzyme C-P lyase (PhnGHIJKLMN) can also act on 2AEP78, as well as akylphosphonates14,15,23. Pathways found in BIRD-1 are represented by black lines, pathways absent from BIRD-1 are shaded grey. Characterised pathways are shown with solid lines, uncharacterised pathways are shown with dashed lines. Transporters found in BIRD-1 are red if Pisensitive, green if Pi-insensitive, and yellow if constitutive. Unknown mechanisms are denoted by a '?'. (B) Phylogenetic tree of AepX, PhnS, and AepS, using the characterised Fe3+ substrate binding protein FBPa from Haemophilus influenzae and Bordetella pertussis as an outgroup. P. putida $=$ Pseudomonas putida BIRD-1, S. stellulata $=$ Stappia stellulata, B. cepacia = Burkholderia cepacia, $\mathrm{B}$. vireti $=$ Bacillus veriti, $\mathrm{S}$. merionis $=$ Streptococcus merionis, $\mathrm{S}$. typhimurium = Salmonella typhimurium, $\mathrm{S}$. diastatochromogenes = Streptomyces diastatochromogenes, B. thuringiensis = Bacillus thuringiensis. $(C)$ Growth $(n=4)$ of P. putida BIRD-1 wild type, $\triangle$ aepXVW, and the complemented mutant. (D), $\triangle$ aepP and the complemented mutant, and (E), the 2AEP null mutant, $\triangle$ aepXVW::aepP::aepSTU. All strains used 2AEP as a sole P (top panel) or $\mathrm{N}$ (bottom panel) source. Error bars denote standard deviation of the mean. 
Y P. putida BIRD-1

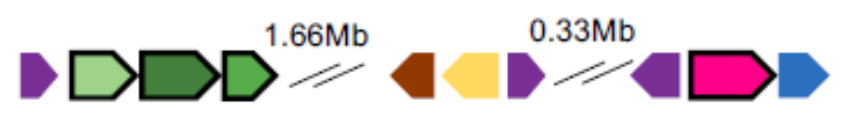

S. meliloti 1021

S. stellulata DSM 5886

A. crassotreae DSM 16950

A. sediminilitorius DSM 29439

$\alpha$

T. aestuarii DSM 15283

S. marina DSM 26895

T. pusilla DSM 6293

T. pusilla DSM 6293

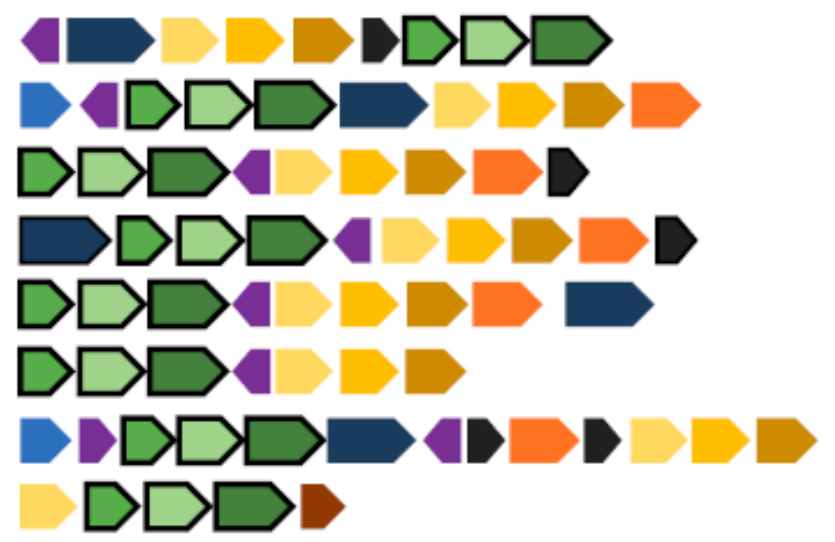

\begin{tabular}{|c|c|}
\hline AepVPfam00005 & PhnR Pfam03466 \\
\hline AepW Pfam00528 & AepP Pfam 07690 \\
\hline AepX $X^{\text {Pfam13343 }}$ & Pi: $\mathrm{Na}^{2+}$ symporter Pfam02690 \\
\hline PhnXPfam13419 & Aminotransferase $\mathrm{Pfam} 0020^{\text {Pan }}$ \\
\hline PhnW Pfam00266 & Oxidoreductase $\mathrm{Pfam01266}^{\text {Pat }}$ \\
\hline $\begin{array}{l}\text { PhnA Afam01663 } \\
\text { PhnYPfam00171 }\end{array}$ & Uncharacterised protein \\
\hline
\end{tabular}

B

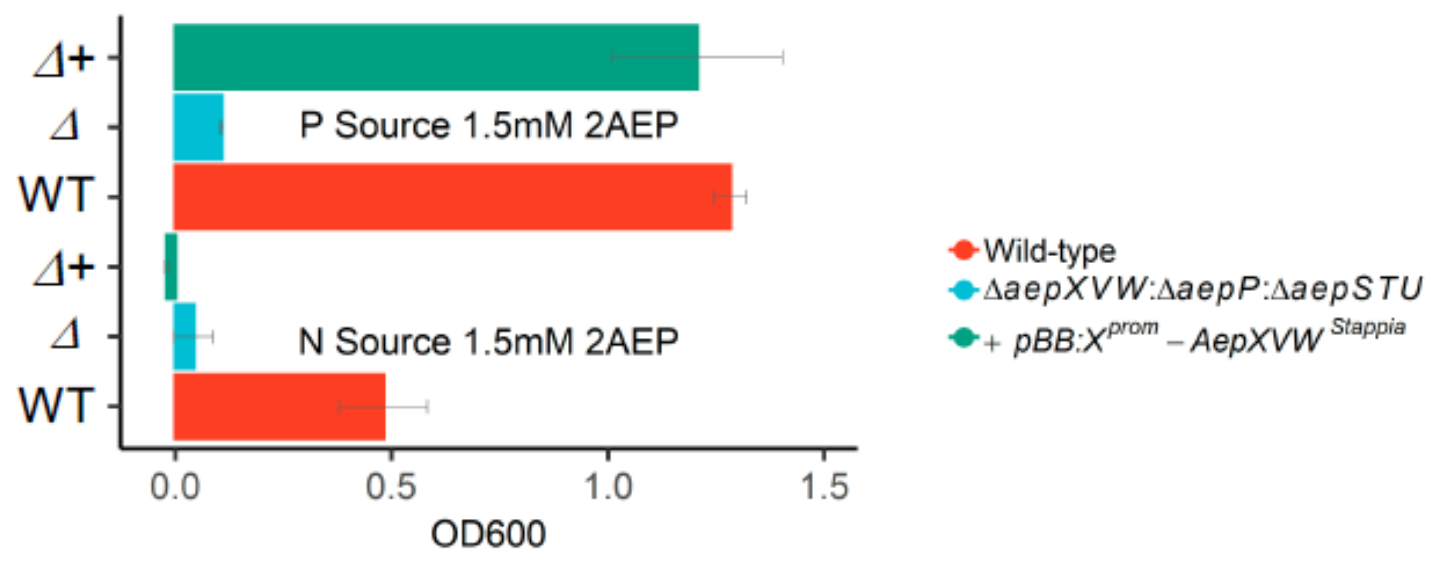

Figure 2

Distribution and functional characterisation of AepXVW in marine bacteria. (A) Genetic neighbourhoods of aepXVW within marine Alpha- and terrestrial Gamma-proteobacteria. Strains shown are Pseudomonas putida BIRD-1, Sinorhizobium meliloti 1021, Stappia stellulata DSM 5886, Aliiroseovarius crassostreae DSM 16950, Aliiroseovarius sediminilitoris DSM 29439, Thalassobius aestuarii DSM 15283, and Shimia marina DSM 26895. ORFs separated on the genome are indicated by breaks with the corresponding gap 
given in megabases (Mb). (B) Growth of the P. putida BIRD-1 triple 2AEP transporter mutant ( $\triangle$ aepXVW:aepP:aepSTU:gm) complemented with aepXVWStappia concatenated with the promoter region from aepXVWBIRD on 2AEP as either a sole $\mathrm{N}(60 \mathrm{~h})$ or $\mathrm{P}(48 \mathrm{~h})$ source. Data represents the mean of triplicates cultures. Error bars denote standard deviation.

\section{S. stellulata}

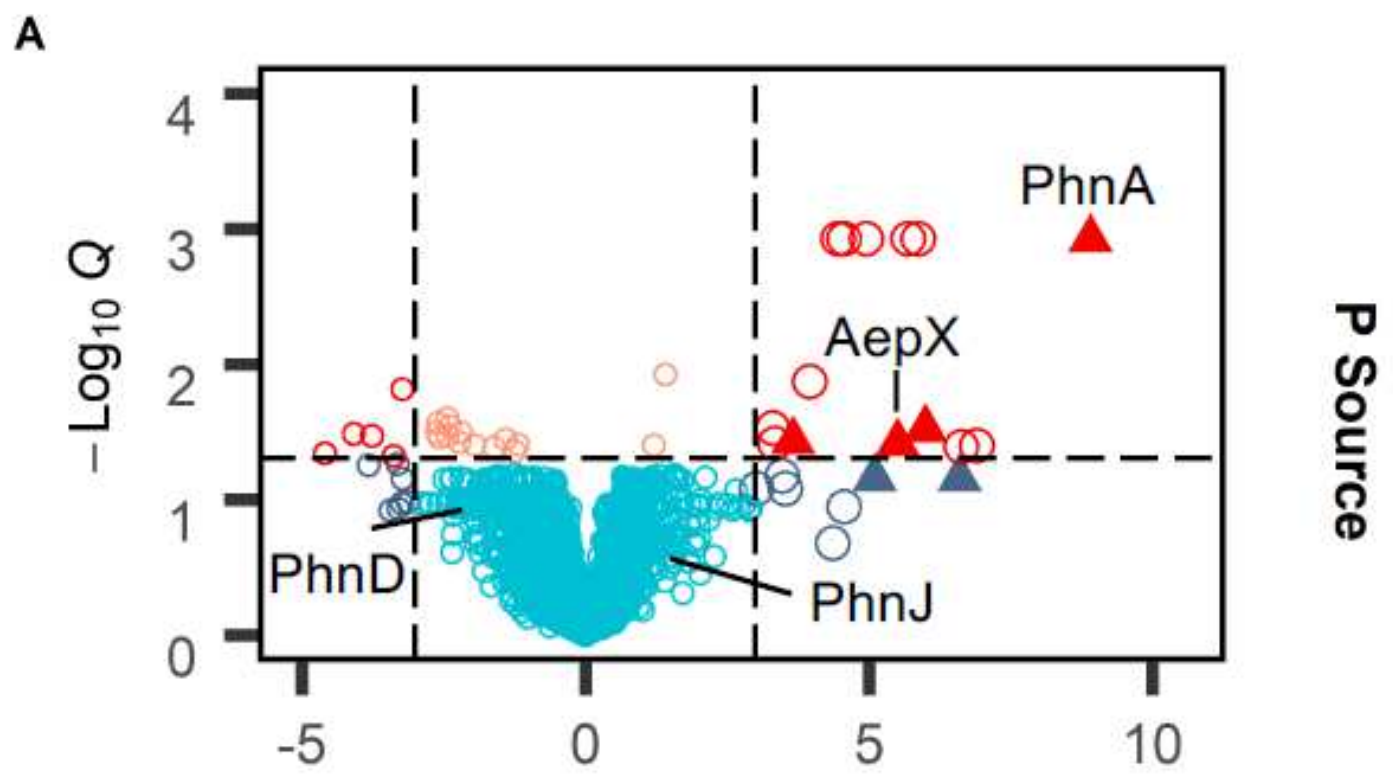

B

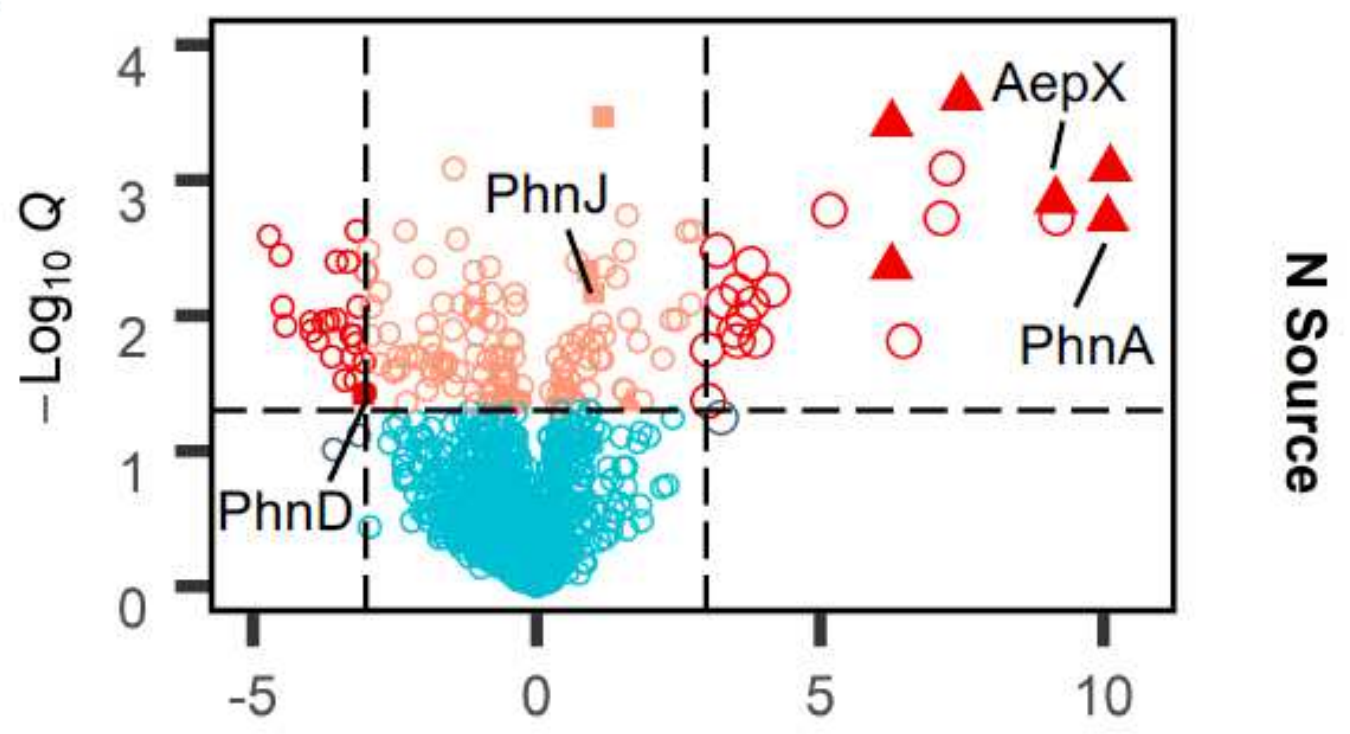

$\log _{2}$ fold change

FC cutoff, 3, q-value cutoff, 0.05

Figure 3 
Proteomic analysis of 2AEP-grown S. stellulata cells. Whole-cell protein expression profiles $(n=3)$ for $S$. stellulata grown using either $\mathrm{Pi}$ or 2AEP as sole $\mathrm{P}$ source (A) or NH4 or 2AEP as the sole $\mathrm{N}$ source (B). Fold change represents the difference in Log2 LFQ values between each treatment and the statistical value on the $Y$ axis is generated from $Q$ values (FDR corrected $P$ values). Members of the aepXVWphnWAY operon are shown as triangles, members of the $\mathrm{CP}$ lyase operon are shown as squares, all other proteins are shown as open circles. Data plotted represents the mean of triplicate cultures.

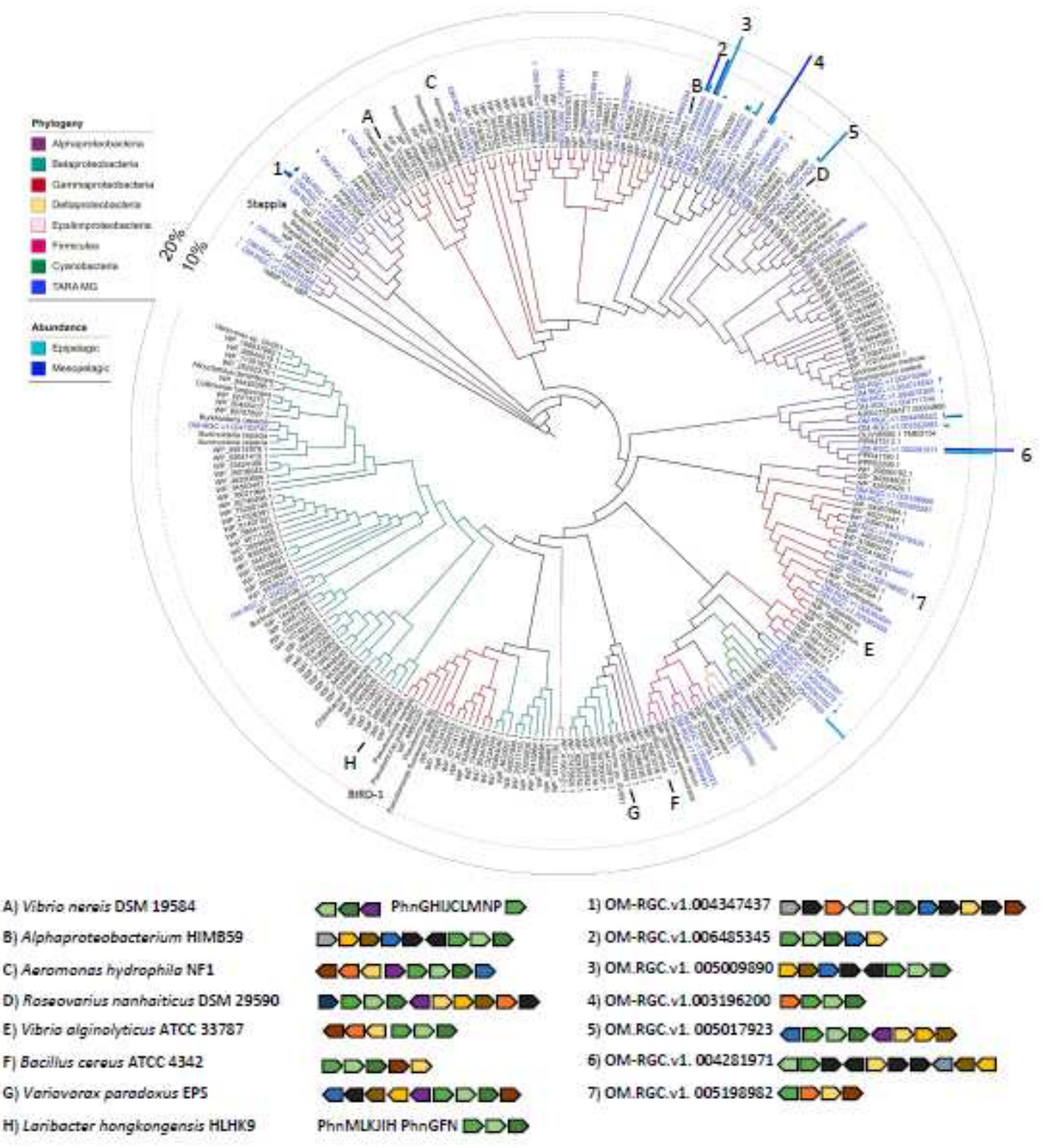

\begin{tabular}{|c|c|c|c|c|c|}
\hline 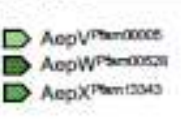 & 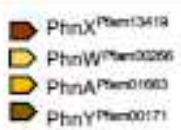 & $\begin{array}{l}D \\
D \\
D\end{array}$ & 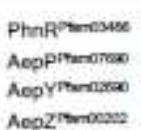 & 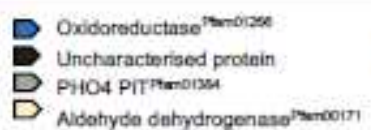 & 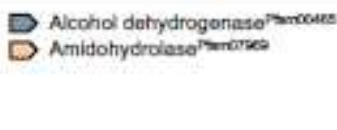 \\
\hline
\end{tabular}

\section{Figure 4}


Phylogenetic and genomic analyses of aepX in marine and terrestrial bacteria. Genetic neighbourhoods for selected aepX homologs are presented adjacent to trees. Numbers indicate environmental OTUs and letters indicate isolates or MAGs/SAGs. Tree topology and branch lengths were calculated by maximum likelihood using the $\mathrm{LG}+\mathrm{F}+\mathrm{I}+\mathrm{G} 4$ model of evolution for amino acid sequences based on 744 sites in IQTREE software 70. A consensus tree was generated using 1000 bootstraps. Branches representing isolates or MAGs/SAGs are colour coded based on their phylogenetic affiliation (see legends). Branches and identifiers for representative environmental OTU sequences (clustered at 0.8) retrieved from the TARA Oceans database are highlighted blue. The outer ring denotes the relative abundance of environmental AepX OTUs using the same colour scheme; $10 \%$ (dashed line) and $20 \%$ (filled line) thresholds are shown for scale. S. stellulata DSM 5886 and P. putida BIRD-1 aepX are labelled. 

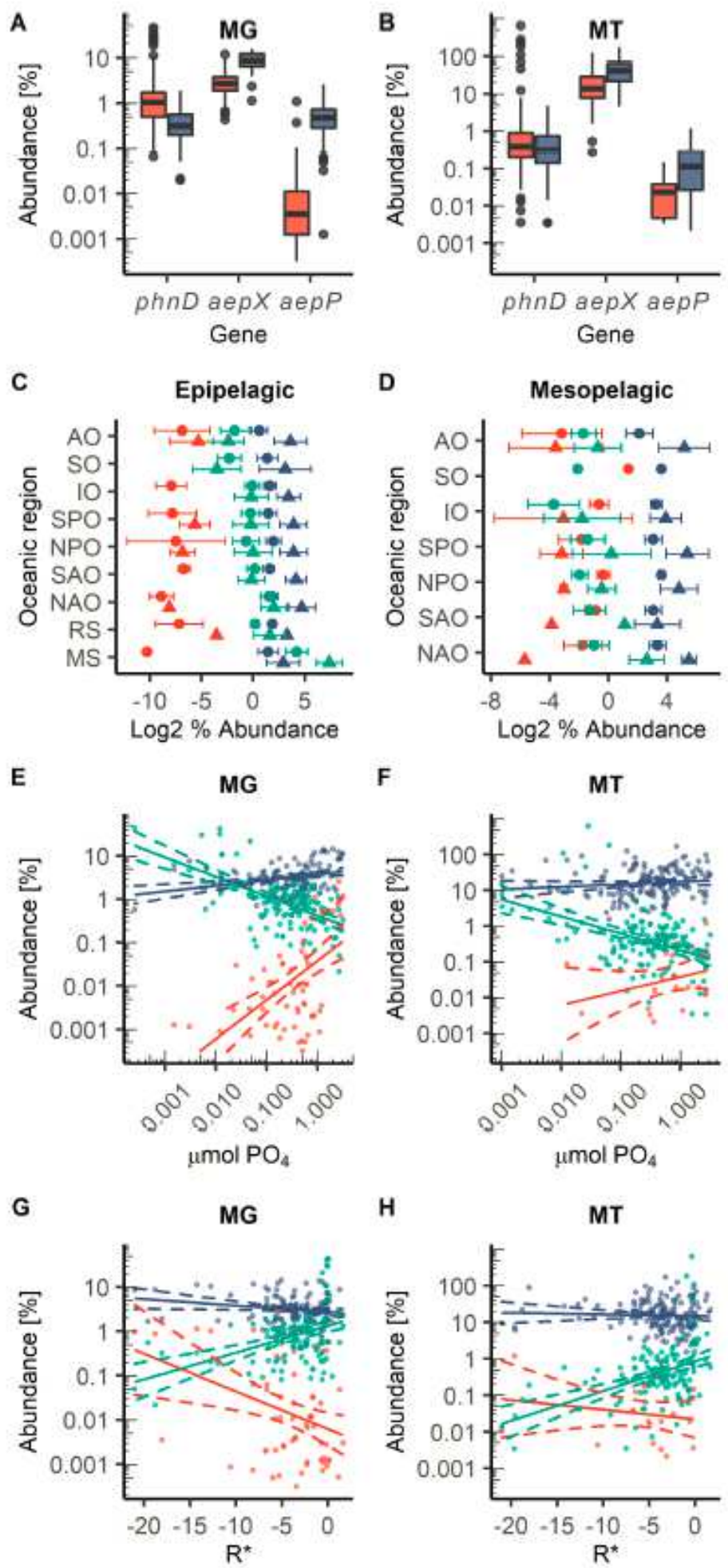

\section{Figure 5}

Distribution and transcriptional regulation of phosphonate transporter genes in the global ocean. Abundance of phnD, aepX, aepP in marine epipelagic (red) and mesopelagic (blue) waters, split by metagenome (MG) (A), and metatranscriptome (MT) (B). Abundance (Log2 \% abundance related to single copy core genes) of phnD, aepX, aepP in MG (circles) and MT (triangles) in epipelagic (C) and mesopelagic (D) waters, split by oceanic region. aepP (red), phnD (green), aepX (blue). AO = Arctic Ocean, 
$\mathrm{SO}=$ Southern Ocean, $\mathrm{IO}=$ Indian Ocean, $\mathrm{SPO}=$ South Pacific Ocean, NPO = North Pacific Ocean, $\mathrm{SAO}=$ South Atlantic Ocean, NAO = North Atlantic Ocean, RS = Red Sea, MS = Mediterranean Sea. The relationship between the standing stock Pi concentration and transporter abundance in the MG (E), (aepX R2 $=0.098^{\star \star \star}$, phnD R2 $=0.340^{\star \star \star}$, aepP R2 $\left.=0.291^{\star \star \star}\right)$ and MT $(\mathrm{F}),($ aepX R2 $=0.007 n s$, phnD R2 $=$ $0.203^{\star \star *}$, aepP R2 = 0.058ns). aepP (red), phnD (green), aepX (blue), ns = not significant, $\star \star \star ~=p<0.001$. The relationship between $\mathrm{R}^{\star}$, a measure of $\mathrm{N}$ vs $\mathrm{P}$ limitation defined as the sum of standing stock nitrate plus nitrite concentration minus $16 \mathrm{x}$ standing stock $\mathrm{Pi}$ concentration, and transporter abundance in the

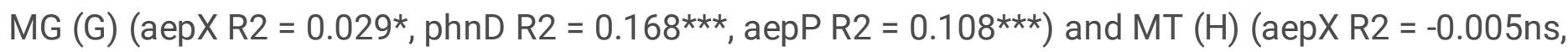

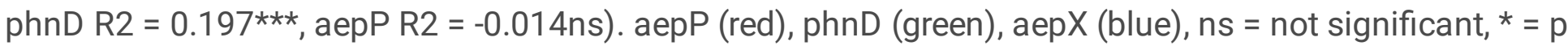
$<0.05, * \star *=p<0.001$.

\section{Supplementary Files}

This is a list of supplementary files associated with this preprint. Click to download.

- MurphyPhosphonatesSuppFigsNov20Final.pptx

- SuppFigure4.docx

- MurphyPhosphonatesSuppTablesNov20Final.docx

- SupplementaryproteomicstableS3.xlsx 